Check for updates

Cite this: Sustainable Energy Fuels, 2017, 1, 1541

Received 19th April 2017

Accepted 20th June 2017

DOI: $10.1039 / \mathrm{c} 7 \mathrm{se} 00206 \mathrm{~h}$

rsc.li/sustainable-energy

\section{Process exploration and assessment for the production of methanol and dimethyl ether from carbon dioxide and water $\dagger$}

\begin{abstract}
A. Hankin (iD * and N. Shah (iD
A thermodynamic, model-based, study was carried out to assess the relative performance of methanol and dimethyl ether (DME) synthesis systems using $\mathrm{CO}$ - and $\mathrm{CO}_{2}$-based syngas feeds. The upstream production of a range of syngas feed compositions was simulated using $\mathrm{CO}_{2}$ and $\mathrm{H}_{2} \mathrm{O}$ as the sole chemical building blocks, a requirement motivated by the increasing constraints on permissible $\mathrm{CO}_{2}$ emissions and the successful adaptation by some industrial methanol plants to the direct utilisation of $\mathrm{CO}_{2}$. The objective was to establish whether the energy requirements and $\mathrm{CO}_{2}$ emissions associated with upstream conversion of $\mathrm{CO}_{2}$ to $\mathrm{CO}$ were justified by increased productivity in the methanol/DME systems. In the first part of the study, the performance of four systems was evaluated and compared in terms of energy efficiency and $\mathrm{CO}_{2}$ conversion: (1) methanol synthesis system, (2) direct DME synthesis system, (3) twostep DME synthesis system with an interposed syngas separation step between the methanol production reactor and methanol dehydration reactor and (4) two-step DME synthesis system with no separation step between the two reactors. Based on equilibrium yields at $250{ }^{\circ} \mathrm{C}$ and 50 bar, the direct DME synthesis system was found to exhibit the highest energy conversion efficiencies with both $\mathrm{CO}_{2}-$ and $\mathrm{CO}$-based syngas. Although this system demonstrated the lowest $\mathrm{CO}_{2}$ emissions per methanol equivalent product with a $\mathrm{CO}$-based feed, the benefits were offset by emissions associated with the upstream conversion of $\mathrm{H}_{2} \mathrm{O}$ and $\mathrm{CO}_{2}$ to $\mathrm{H}_{2}$ and $\mathrm{CO}$, evaluated in the second part of the study. It was determined that $\mathrm{CO}_{2}$ could be utilised directly in the direct DME synthesis route, whereas upstream conversion of $\mathrm{CO}_{2}$ to $\mathrm{CO}$ was necessary to achieve effective yields in the methanol/two-step DME systems. CO-based syngas production via high temperature co-electrolysis of $\mathrm{H}_{2} \mathrm{O}$ and $\mathrm{CO}_{2}$, or alternatively high temperature $\mathrm{CO}_{2}$ electrolysis coupled with the water-gas shift process, was identified as the best technology based on energy consumption and $\mathrm{CO}_{2}$ utilisation.
\end{abstract}

\section{Introduction}

Presently, dense energy carriers with applications in energy storage, such as methanol and dimethyl ether (DME) are, for economic reasons, derived principally from fossil fuels. ${ }^{1}$ Typically, syngas is first generated from either natural gas or coal and subsequently converted to methanol, DME or other liquid hydrocarbons via the Fischer-Tropsch process. These processes release $\mathrm{CO}_{2}$. For example, conventional methanol production plants can release over $5 \mathrm{t}\left(\mathrm{CO}_{2}\right) / \mathrm{t}($ methanol $),{ }^{2}$ depending on the feedstock. However, emissions of $\mathrm{CO}_{2}$ and other greenhouse gases (GHG) into the atmosphere are becoming a global concern and regulations requiring their minimisation are being put in place. $^{3}$ One of the consequences will be the gradual decarbonisation of energy sources, which is expected to

Department of Chemical Engineering, Imperial College London, London, SW7 2AZ, UK. E-mail:anna.hankin@imperial.ac.uk

$\dagger$ Electronic supplementary information (ESI) available. See DOI: $10.1039 / \mathrm{c} 7 \mathrm{se} 00206 \mathrm{~h}$ decrease the overall demand for coal and gas. ${ }^{4}$ Consequently, alternative choices of raw materials, as well as the re-design of processes that would enable the minimisation of $\mathrm{CO}_{2}$ emissions, are required. Indeed this is the basis for the concept of the methanol economy, ${ }^{5}$ in which $\mathrm{CO}_{2}$ is recycled into methanol and DME for energy storage or conversion to other synthetic fuels in order to reduce dependence on fossil fuels and to mitigate the rate of global warming.

Investigation of direct and indirect utilisation of $\mathrm{CO}_{2}$ in methanol and DME synthesis processes was the focus of this study because of their industrial importance and large scale production. ${ }^{1}$ Methanol is used in the manufacture of chemicals, such as formaldehyde, methyl tert-butyl ether (MTBE) and acetic acid, as well as plastics. It can be transformed into petrochemicals or blended with them for use in internal combustion engines; ${ }^{6}$ it can also be used in fuel cells. ${ }^{7} \mathrm{DME}$, the dehydration product of methanol, is a non-toxic chemical with uses in household products, aerosol propellants, paints and, like methanol, can be used as a fuel either directly or in a blend, ${ }^{7,8}$ for example with liquefied petroleum gas (LPG). DME has 
already replaced diesel fuel in the engines of some vehicles, demonstrating improved environmental performance., ${ }^{\mathbf{9 1 0}}$ The advantage of both methanol and dimethyl ether is that they do not generate carbonaceous particulate matter upon combustion.

Encouragingly, several projects have now demonstrated that methanol can be synthesized directly from $\mathrm{CO}_{2}$ captured from large point sources, such as power plants, and $\mathrm{H}_{2}$ generated electrochemically from $\mathrm{H}_{2} \mathrm{O} .^{\mathbf{1 1 - 1 4}}$ These processes utilise modified catalysts with greater tolerance to water build-up and also larger fractions of hydrogen to carbon in the system feeds than those used in conventional processes.

The feasibility of direct $\mathrm{CO}_{2}$ utilisation on an industrial scale confirms that the widely reported problems associated with slow $\mathrm{CO}_{2}$ dehydrogenation kinetics and catalyst deactivation are surmountable. Hence, the purpose of this study was to reexamine and compare the thermodynamic constraints on methanol as well as DME syntheses from CO- and $\mathrm{CO}_{2}$-based syngas using system analysis in Aspen Plus V8.8. The goal was to identify the theoretical differences between system efficiencies when $\mathrm{CO}$ and $\mathrm{CO}_{2}$ were the principal sources of carbon to the synthesis steps and whether in certain situations a $\mathrm{CO}_{2}$-based feed could be preferable to a CO-based one. Equilibrium syngas conversion was investigated in four systems:

1. Methanol synthesis;

2. Direct DME synthesis (methanol dehydration occurring simultaneously with $\mathrm{CO} / \mathrm{CO}_{2}$ hydrogenation);

3. Two-step DME synthesis (methanol synthesis and methanol dehydration occurring in two separate stages) with an interposed unreacted syngas separation step;

4. Two-step DME synthesis with no separation step between the two reactors.

In the first part of the study, system efficiencies and extents of $\mathrm{CO}_{2}$ conversion were examined for Stage 2 in Fig. 1 as a function of hydrogen to total carbon molar ratios, $\mathrm{H}_{2}$ : $\left(\mathrm{CO}_{2}+\right.$ $\mathrm{CO})$, in the system feed. The total molar carbon flux : $\left(\mathrm{CO}_{2}+\mathrm{CO}\right)$ was fixed, while the $\mathrm{CO}_{2}$ : CO ratio was varied between 1 and $\approx 0$ in order to determine the theoretical limitations imposed when $\mathrm{CO}_{2}$ rather than $\mathrm{CO}$ was supplied to the conversion systems. Efficiencies were evaluated as quotients of the net energies produced in Stage 2 and the energies contained in the syngas entering Stage 2. Net energies were computed based on energies

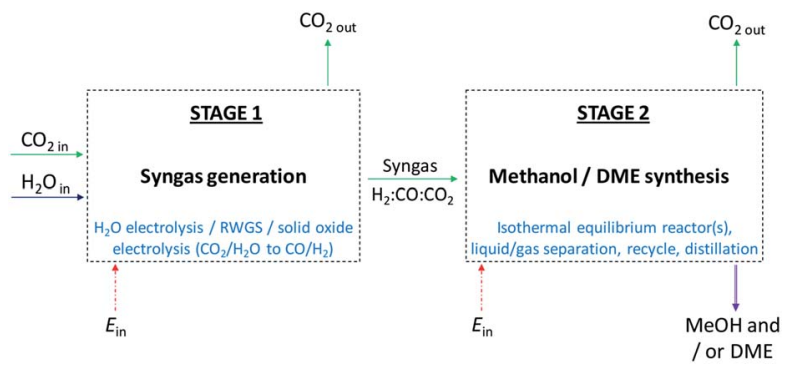

Fig. 1 Principal stages in methanol and DME syntheses from $\mathrm{CO}_{2}$ and $\mathrm{H}_{2} \mathrm{O}$. In Stage 1, $\mathrm{CO}_{2}$ and $\mathrm{H}_{2} \mathrm{O}$ are converted to $\mathrm{CO}$ and $\mathrm{H}_{2}$ (syngas); in cases where $\mathrm{CO}_{2}$ it utilised directly only $\mathrm{H}_{2}$ is generated in Stage 1. In Stage 2, syngas is converted to methanol and/or DME. extracted in the form of methanol and DME and energies required to support the operation of heaters, compressors and distillation columns in the systems. The energy contained in the syngas was based on the lower heating values of hydrogen and carbon monoxide. Various energy saving mechanisms were examined, including the combustion of vented gases and the coupling of heat exchangers.

In the second part of the study, possible routes to syngas compositions identified as optimum for Stage 2 were explored. Energy requirements were estimated and compared against the benefits of utilising $\mathrm{CO}$ over $\mathrm{CO}_{2}$ in Stage 2. Decontaminated $\mathrm{CO}_{2}$ and $\mathrm{H}_{2} \mathrm{O}$ were assumed to be the sole building blocks for syngas generation in Stage 1, as shown in Fig. 1, hence respecting the system boundary.

Potential disparities between thermodynamic predictions and kinetics were not considered in this study because the broad range of feed compositions under investigation here has not been covered by a complete set of kinetic data and because the wide range of kinetic data available for different catalysts cannot be readily distilled to parameters applicable across the whole range of syngas compositions.

\section{Industrial processes}

The chemical reactions and process layouts for methanol and DME synthesis, as well as examples of industrial processes, are described below.

\section{Industrial production of methanol and dimethyl ether}

Methanol production from syngas. Methanol is principally formed by the hydrogenation of CO (1) but can also be synthesized by hydrogenation of $\mathrm{CO}_{2}(2)$. The water gas shift reaction (WGS) (3) takes place simultaneously with (1) and (2). Copper based catalysts such as $\mathrm{Cu} / \mathrm{ZnO}$, employed most commonly, catalyse all three processes. ${ }^{11,13,15}$

A general process layout for industrial methanol production is shown in Fig. 2. Fresh syngas in fed into a methanol reactor, which is operated at temperatures in the range of $150-300{ }^{\circ} \mathrm{C}$ and under pressures in the range 10-100 bar, ${ }^{11}$ although typical

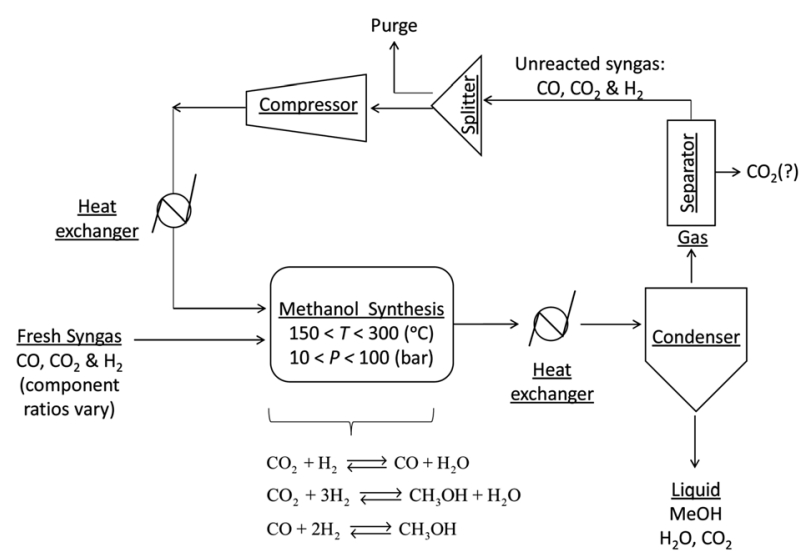

Fig. 2 A general process layout for a commercial methanol production system. 
conditions are $250-260{ }^{\circ} \mathrm{C}$ and $50-60$ bar. A large number of reactor designs have been commercialised, but generally these are operated either under adiabatic or isothermal conditions. ${ }^{7}$ In both reactor types, the control of reactor temperatures is one of the principal challenges because reactions (1)-(3) are exothermic and can cause temperatures to rise above $300{ }^{\circ} \mathrm{C}$, at which catalyst deactivation often occurs. ${ }^{1}$

$$
\begin{gathered}
\mathrm{CO}+2 \mathrm{H}_{2} \rightleftarrows \mathrm{CH}_{3} \mathrm{OH} \\
\mathrm{CO}_{2}+3 \mathrm{H}_{2} \rightleftarrows \mathrm{CH}_{3} \mathrm{OH}+\mathrm{H}_{2} \mathrm{O} \\
\mathrm{CO}+\mathrm{H}_{2} \mathrm{O} \underset{\text { RWGS }}{\stackrel{\text { WGS }}{\rightleftarrows}} \mathrm{CO}_{2}+\mathrm{H}_{2}
\end{gathered}
$$

The reactor effluent, which contains methanol, water and unreacted syngas is cooled to condense out the methanol, water and any absorbed $\mathrm{CO}_{2}$. Methanol is generally separated by distillation. ${ }^{\mathbf{1 1}}$ After separation from methanol and water, the unreacted gases may be processed further, for example to remove the $\mathrm{CO}_{2}$, and then recycled into the reactor. $\mathrm{CO}_{2}$ is then vented or recycled further upstream.

Although $\mathrm{CO}_{2}$ is reported to have an adverse effect on methanol synthesis rates, studies with isotopic labelling ${ }^{16}$ on a commercial $\mathrm{Cu} / \mathrm{ZnO} / \mathrm{Al}_{2} \mathrm{O}_{3}$ catalyst showed that in fact a certain quantity of $\mathrm{CO}_{2}$ in the syngas (4-8\%) is essential to make conversion to methanol possible as $\mathrm{CO}_{2}$ is the principal source of carbon in the methanol ${ }^{7,17}$ and also to protect catalysts from deactivation. ${ }^{18}$

There are presently three industrial methanol synthesis plants that exclusively utilise $\mathrm{CO}_{2}$ and $\mathrm{H}_{2}$. Mitsui Chemicals' Osaka Works combines purified $\mathrm{CO}_{2}$ exhaust with $\mathrm{H}_{2}$ produced by water electrolysis to generate methanol. ${ }^{11}$ Catalysts able to tolerate high water levels, caused by reaction (2) and the reverse water gas shift reaction (3) (RWGS), were specifically developed for these conditions. $\mathrm{CO}_{2}$ was not removed from the recycle loop, while a portion of the unreacted gases was combusted to supply heat to other parts of the system.

Carbon Recycling International (CRI) produces $4000 \mathrm{t}$ per year of renewable methanol (Vulcanol ${ }^{\mathrm{TM}}$ ) by direct synthesis using carbon dioxide, sourced from flue gas released by a geothermal power plant, and hydrogen, generated from renewably powered water electrolysis. ${ }^{12}$ This process is reported to reduce carbon emissions by more than $85 \%$ compared with plants that utilise syngas derived from fossil fuels. ${ }^{19}$ The methanol is subsequently blended with gasoline to power cars. Two methods are potentially used to achieve $\mathrm{CO}_{2}$ and $\mathrm{H}_{2}$ conversion. In the first method, the $\mathrm{CO}_{2}$ and $\mathrm{H}_{2}$, undergo the RWGS reaction; ${ }^{20}$ following the removal of water from the product stream by condensation, and separation of $\mathrm{CO}_{2}$ by isothermal compression, hydrogen is added to the remaining product stream to achieve the ratio $\mathrm{H}_{2}$ : CO of $2: 1$, before being fed into the methanol reactor. In the second method, $\mathrm{H}_{2}$ and $\mathrm{CO}_{2}$, in a ratio of $7: 2$, are reacted directly to form methanol and CO.

Blue Fuel Energy is amongst the next producers of renewable methanol from captured $\mathrm{CO}_{2}$ and $\mathrm{H}_{2}$ produced in an electrolyser powered by renewables, and to convert it to gasoline. ${ }^{\mathbf{1 4}} \mathrm{Net}$ greenhouse gas (GHG) emissions are expected to be heavily influenced by the $\mathrm{H}_{2}$ production process; ${ }^{21}$ however, preliminary figures suggest a reduction in $\mathrm{CO}_{2}$ emissions by $65-84 \%$ relative to fossil fuel based processes. ${ }^{19}$

In terms of capital investment, methanol synthesis from $\mathrm{CO}_{2}$ and $\mathrm{H}_{2}$ has been estimated to be approximately the same as that for a conventional plant. ${ }^{1}$ The principal limiting factor for scaleup of such processes is said to be the availability and price of $\mathrm{CO}_{2}$ and $\mathrm{H}_{2}$ and the source of electrical energy.

The systems reported to date use a range of $\mathrm{H}_{2}$ : carbon ratios, depending on whether $\mathrm{CO}$ or $\mathrm{CO}_{2}$ is used in the feed. A stoichiometric ratio of 2 , as defined by eqn (4), is preferred for syngas with high $\mathrm{CO}: \mathrm{CO}_{2}$ ratios.

$$
S_{\mathrm{R}}=\frac{\left(\mathrm{H}_{2}-\mathrm{CO}_{2}\right)}{\left(\mathrm{CO}+\mathrm{CO}_{2}\right)}
$$

However, often for kinetic reasons a value slightly higher than 2 is employed in industry. For example, the isothermal Lurgi Methanol Converter uses $S_{\mathrm{R}}=2.05-2.1$; $^{22}$ Haldor Topsoe use $S_{\mathrm{R}}=2$. On the other hand, for processes employing direct conversion of $\mathrm{CO}_{2}$ and $\mathrm{H}_{2}$ to methanol, a ratio of 3.5 was used ${ }^{13}$ and a ratio of 5.0 was specified as optimum. ${ }^{11}$ The higher than 2 ratio is designed to decrease the molar fraction of water so as to limit its adsorption onto the catalyst. In this way, the decrease in the methanol production efficiency can be mitigated. One of the objectives of this study was to identify the optimum thermodynamic $\mathrm{H}_{2}$ : $\mathrm{CO}_{2}$ ratios in the system feeds when $\mathrm{CO}_{2}$ was utilised directly for the production of methanol/DME.

Dimethyl ether production from syngas. Dimethyl ether is produced via the dehydration of methanol by reaction (5) over solid acid catalysts such as gamma alumina $\left(\gamma-\mathrm{Al}_{2} \mathrm{O}_{3}\right)$, silica alumina, activated alumina or ZSM-5 (zeolite-based catalysts). ${ }^{2324}$ This process requires temperatures and pressures in the ranges of $210-290{ }^{\circ} \mathrm{C}$ and $30-100$ bar, respectively, and hence is wholly compatible with methanol production conditions.

$$
2 \mathrm{CH}_{3} \mathrm{OH} \Leftrightarrow \mathrm{CH}_{3} \mathrm{OCH}_{3}+\mathrm{H}_{2} \mathrm{O}
$$

Reaction (5) can take place in a designated reactor, into which methanol, produced in a separate reactor via (1), (3) and/ or (2), is fed. Alternatively, both the production and dehydration of methanol can take place in the same reactor that utilises bifunctional catalysts, such as $\mathrm{Cu} / \mathrm{ZnO} / \gamma-\mathrm{Al}_{2} \mathrm{O}_{3}$. The former and the latter production methods are commonly referred to as the 'two-step process' and direct 'one-step process', respectively.

If only $\mathrm{CO}$ and $\mathrm{H}_{2}$ are present in the reactor system feed, the overall reaction is:

$$
3 \mathrm{CO}+3 \mathrm{H}_{2} \rightleftarrows \mathrm{CH}_{3} \mathrm{OCH}_{3}+\mathrm{CO}_{2}
$$

The stoichiometric requirement for the $\mathrm{H}_{2}$ : CO ratio in the feed is $1: 1$. Notably, this process will result in the generation of $\mathrm{CO}_{2}$. This drawback could be resolved by recycling and using $\mathrm{CO}_{2}$ in the process by which syngas is produced, be it dry methane reforming or reduction to $\mathrm{CO}$ in high temperature 
solid oxide electrolysers. However, in terms of $\mathrm{CO}_{2}$ emissions, the preferred option would be to minimise the generation of $\mathrm{CO}_{2}$, such that separation and recycle costs could be minimised, and that the DME production process would always result in net $\mathrm{CO}_{2}$ utilisation. If $\mathrm{CO}_{2}$ is present in the system feed together with $\mathrm{CO}$ and $\mathrm{H}_{2}$, the overall process reaction becomes:

$$
2 \mathrm{CO}+4 \mathrm{H}_{2} \rightleftarrows \mathrm{CH}_{3} \mathrm{OCH}_{3}+\mathrm{H}_{2} \mathrm{O}
$$

Hence, net $\mathrm{CO}_{2}$ production by the reactor could be minimised, provided the ratio of $\mathrm{CO}_{2}: \mathrm{CO}: \mathrm{H}_{2}$ in the system feed is optimised in order for thermodynamics and kinetics to be favourable.

An additional issue is the generation of water by reactions (5) and (7), resulting in $\mathrm{CO}_{2}$ and $\mathrm{H}_{2}$ production by the WGS reaction (3). While $\mathrm{H}_{2}$ is beneficial for CO conversion via reaction (1), the production of $\mathrm{CO}_{2}$ is not and serves to reverse the benefits of reaction (2). If one of the principal goals is $\mathrm{CO}_{2}$ mitigation, then the constraints on the process must include the requirement that less $\mathrm{CO}_{2}$ is produced than is consumed. Therefore, this places a lower limit on the $\mathrm{H}_{2}:\left(\mathrm{CO}_{2}+\mathrm{CO}\right)$ ratio that can be used in the system feed. The degree of syngas conversion and $\mathrm{CO}_{2}$ emissions depend greatly on the type of process used: there are two principal options.

Two-step process. The two-step process is the more conventional method for DME production and is currently employed by companies such as Haldor Topsoe, Toyo Engineering (TEC), Oberon Fuels, BioDME and Lurgi (Air Products). With this approach, a methanol dehydration reactor, typically a fixed bed catalytic system, may be connected to an existing methanol production facility and used when required. Furthermore, the separate dehydration step is reported to require low capital investment, provided there is high feedstock availability. The maturity of the available technology for obtaining methanol and the relative simplicity of methanol dehydration are the great attractions of the two-step process. Furthermore, the limited activity of the solid acid dehydration catalysts for the water gas shift reaction at low temperatures results in only small amounts of $\mathrm{CO}_{2}$ generated by reaction (3) in the second step; the same is not true for the one-step system, where the catalyst used for converting syngas to methanol also has a high activity for the WGS reaction.

One-step process. A higher syngas conversion and molar methanol equivalent productivity (MEP), defined in eqn (8), ${ }^{25}$ can theoretically be achieved in the direct process compared to the two-step process:

$$
\mathrm{MEP}=[\mathrm{MeOH}]+2[\mathrm{DME}]
$$

Productivity is improved in the one-step system because in situ dehydration of methanol displaces the equilibrium in eqn (1) and (2); hence, methanol yields and, consequently, DME yields increase. Due to the synergy between reactions (1)-(3) and (5), syngas conversion to DME gives higher equilibrium conversions than syngas conversion to methanol. ${ }^{7}$ Industrial feasibility studies have already been carried out, ${ }^{26}$ where several companies tested a $100 \mathrm{t}_{(\mathrm{DME})} \mathrm{d}^{-1}$ demonstration plant, which accomplished a $96 \%$ synthesis gas $\left(\mathrm{H}_{2}: \mathrm{CO}=1.0\right.$, derived from natural gas) conversion to DME. However, since the 2006 report of isolated tests, no large scale production of DME by the direct process is taking place.

Improvement of the methanol equivalent productivity by the one-step DME process over the methanol process has also been demonstrated both experimentally $\left(250{ }^{\circ} \mathrm{C}\right.$ and 52 bar $)$ and numerically ${ }^{25,27}$ by academic research. However, because a mixture of $\mathrm{DME}$ and $\mathrm{CO}_{2}$ is formed in the one-step process, more downstream separation technologies will be required with this method than with the two-step process because of the high degree of association of the two molecules. ${ }^{28}$ Concurrent DME and $\mathrm{CO}_{2}$ separation from unreacted syngas will be necessary if the reactor operates with a $\mathrm{H}_{2}$ : CO mixture. For example, DME and $\mathrm{CO}_{2}$ can be removed simultaneously with a scrubbing solvent of methanol and $\mathrm{DME} ;^{28}$ subsequently further processing to separate DME from $\mathrm{CO}_{2}$ and recover the solvent is required. However, DME separation becomes more straightforward if the reactor is able to process $\mathrm{CO}_{2}$ and hence $\mathrm{CO}_{2}$ can remain in the recycle loop. Separation of DME alone may be accomplished with water as the scrubbing solvent ${ }^{23}$ and a flash separator. Consequently, recovery of DME alone will have a lesser effect on the overall energy efficiency of the process.

It is imperative to quantify the $\mathrm{CO}_{2}$ output from a given system. For example, in the one-step process the formation of water by reaction (5) results in more $\mathrm{CO}_{2}$ being produced than consumed. This point is evident in Fig. 3, which shows per-pass conversion of $\mathrm{CO}_{2}$ and where negative conversion signifies $\mathrm{CO}_{2}$ formation. $\mathrm{CO}_{2}$ production increases with the proportion of $\mathrm{CO}$ in the system feed. Consequently, operating conditions must be identified where energy efficiency is maximised while $\mathrm{CO}_{2}$ emissions are minimised. Additionally, $\mathrm{CO}_{2}$ may be recycled.

A further drawback of the one-step system is that, in practice, catalyst activity may become inhibited by water build-up from

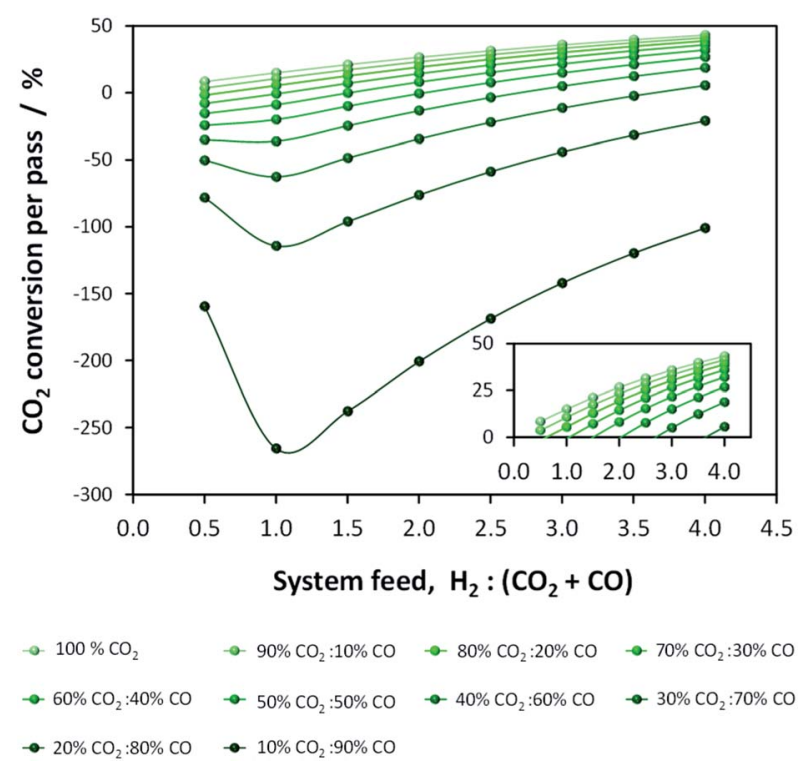

Fig. 3 Equilibrium $\mathrm{CO}_{2}$ conversion in the direct DME process (no recycle) at $250^{\circ} \mathrm{C}$ and 50 bar. 
the methanol dehydration process. However, judicious reactor designs have been proposed to mitigate this issue. ${ }^{31}$

In summary, optimum operating conditions are well understood for methanol and DME synthesis systems operating with $\mathrm{H}_{2}$ and $\mathrm{CO}$ in the feed. Hydrogen to carbon monoxide ratios of 2 and 1 are preferred for the methanol/two-step DME synthesis systems and direct DME synthesis system, respectively. Considerably less is known about processes using $\mathrm{CO}_{2}$ and $\mathrm{CO} / \mathrm{CO}_{2}$ blends instead of $\mathrm{CO}$, especially when $\mathrm{CO}_{2}$ is introduced into the recycle loop. Hence, the impact of $\mathrm{CO}_{2}$ on equilibrium yields of methanol and DME was examined in this study, with focus on system performance and $\mathrm{CO}_{2}$ conversion.

\section{Process assessment methodology}

Syngas conversion rates per pass are typically far below equilibrium values and hence the unconverted syngas is separated from the reaction products and recycled back into the reactors for methanol synthesis or direct DME synthesis. In most industrial systems $\mathrm{CO}_{2}$ is not included in the recycle and is either vented or utilised upstream. However, if the process is to achieve positive net $\mathrm{CO}_{2}$ conversion then $\mathrm{CO}_{2}$ could be recycled together with $\mathrm{CO}$ and $\mathrm{H}_{2}$ and hence this separation step is obviated. Whilst recycle would maximise $\mathrm{CO}_{2}$ conversion, the resultant relative ratios of $\mathrm{H}_{2}: \mathrm{CO}_{2}: \mathrm{CO}$ in the recycle loop could be significantly different to those in the system feed, which would in turn alter the conversions and yields. Furthermore, the amount of energy contained in the methanol and/or DME product(s) will be offset by the operating energy requirements of multiple system components, such as heat exchangers, compressors and distillation columns. Ultimately, the best system operating conditions will be those at which the energy efficiency is maximised. Hence, the objective of the present study was to include all of the above considerations in the evaluation and comparison of the energy outputs and energy requirements for 4 different systems: methanol synthesis, direct DME synthesis, 2-step DME synthesis with an interposed syngas separation step and 2-step DME synthesis with no separation step between the two reactors. The three DME synthesis schemes are shown in Fig. 4; the methanol synthesis scheme is analogous to that shown in Fig. 4a but without the extra methanol dehydration step.

Equilibrium syngas conversions were computed in Aspen Plus V8.8 using the Peng-Robinson equation of state; reactionspecific scenarios were simulated in the REquil reactor (rigorous equilibrium reactor based on stoichiometric approach) at a fixed temperature of $250{ }^{\circ} \mathrm{C}$ and pressure of 50 bar. Results are presented as a function of hydrogen to total carbon molar ratios, $\mathrm{H}_{2}:\left(\mathrm{CO}_{2}+\mathrm{CO}\right)$, in the system feed. The total molar carbon flux : $\left(\mathrm{CO}_{2}+\mathrm{CO}\right)$ was fixed, while the $\mathrm{CO}_{2}$ : CO ratio was varied between 1 and $\approx 0$. The relative methanol yields from methanol synthesis were also compared with the methanol equivalent product (MEP), computed using eqn (8), from direct DME synthesis. In these simulations the formation of by-products such as alkanes (methane, ethane, propane and other light hydrocarbons ${ }^{23}$ ), due to $<100 \%$ catalyst selectivity, ${ }^{29}$

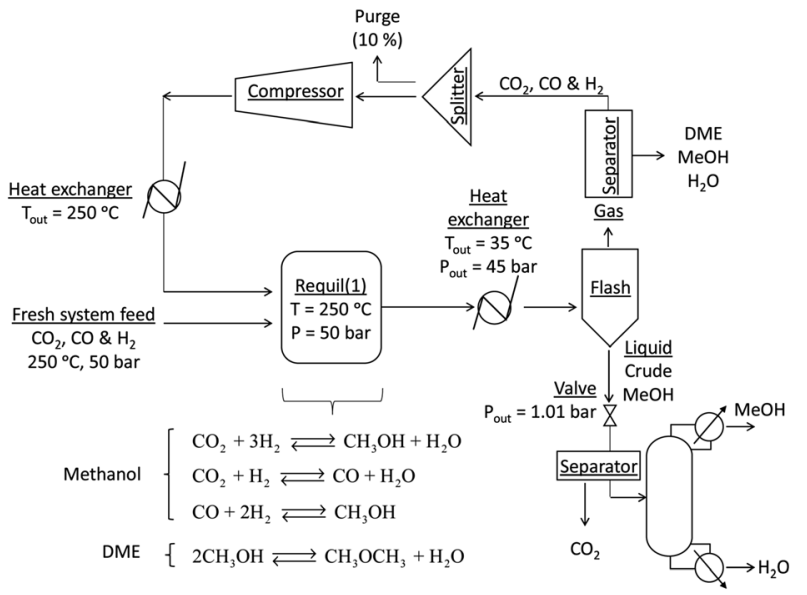

(a)

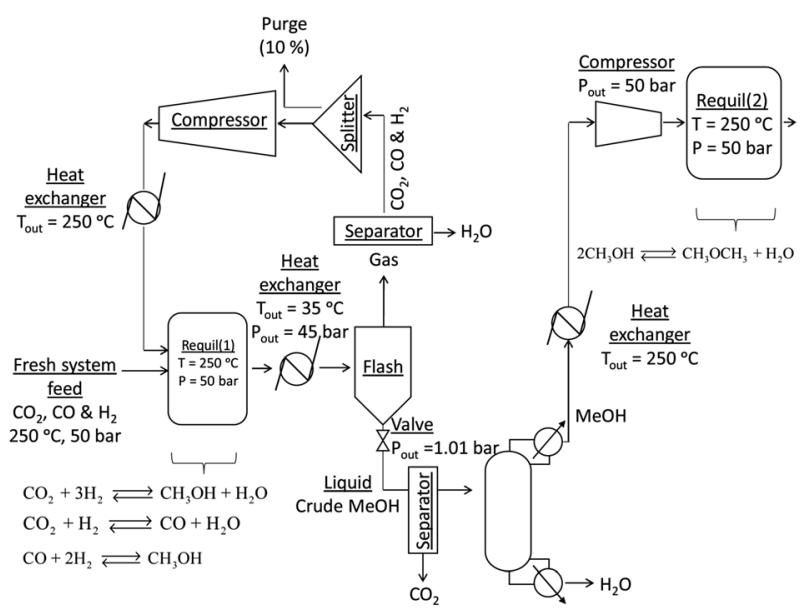

(b)

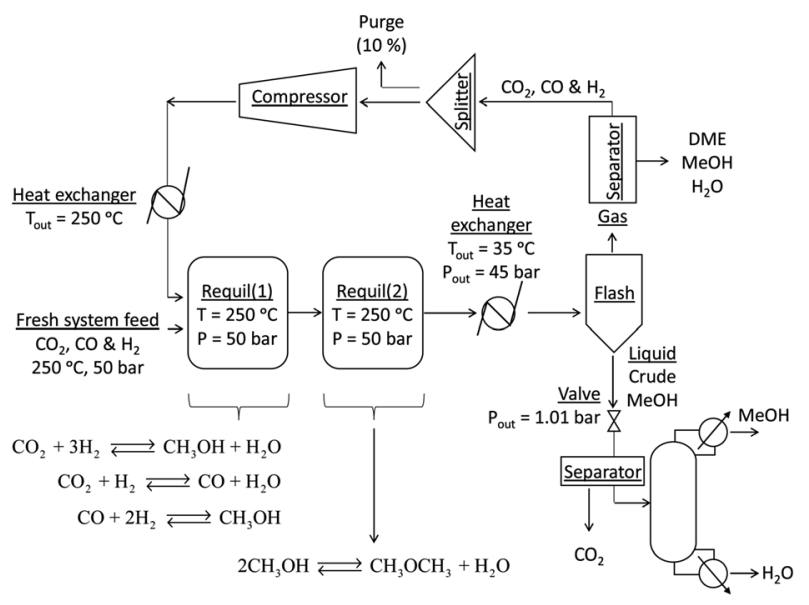

(c)

Fig. 4 Schematics of process layouts for direct and indirect DME synthesis from syngas.

was neglected. The methanol and DME yields from the CO and $\mathrm{CO}_{2}$ molar concentrations in the feed were computed according to eqn (9) and (10), respectively. 


$$
\begin{aligned}
\eta_{\mathrm{MeOH}} & =\frac{[\mathrm{MeOH}]_{\mathrm{out}}}{\left(\left[\mathrm{CO}_{2}\right]+[\mathrm{CO}]\right)_{\mathrm{in}}} \\
\eta_{\mathrm{DME}} & =\frac{2 \times[\mathrm{DME}]_{\mathrm{out}}}{\left(\left[\mathrm{CO}_{2}\right]+[\mathrm{CO}]\right)_{\mathrm{in}}}
\end{aligned}
$$

\section{System streams}

In all systems fresh syngas entered the first reactor pre-heated and pre-pressurized. In the methanol system and in systems (a) and (b) the output streams from the first reactor were cooled in heat exchangers and condensed in flash columns. In system (c) the product stream from the first reactor underwent further conversion in the second reactor before being cooled and passed through a condenser. In system (b) the liquid stream from the flash column containing principally methanol, water and a small molar fraction of $\mathrm{CO}_{2}$ was expanded to atmospheric pressure in a valve and processed in a distillation column in order to obtain a concentrated liquid methanol stream. The methanol was then re-heated, re-pressurised and dehydrated to DME. In all systems a 5 bar pressure drop in the recycle loops was assumed. ${ }^{30}$

In all four systems, $90 \%$ of the unreacted syngas from the flash column was re-pressurised to 50 bar, re-heated to match the temperature and pressure of the fresh syngas and recirculated back into the first reactor. The remaining 10\% was purged to avoid build-up of unreacted gas components. In systems (a) and (b) the DME was removed from the unreacted gases using idealised separators. In practice, DME removal could be achieved using a scrubbing solvent such as water. ${ }^{23}$ Energy requirements for this step were not considered explicitly in this study. Neither the separation of the three syngas components from each other to enable the adjustment of their ratios in the recycle loop nor the addition of specific gases to the recycle loop was considered. Hence, the gas ratios in the reactor feed were typically different to those in the system feed.

\section{Reactors}

The reactors were assumed to operate under isothermal conditions. In practice the syngas temperature at the inlet is set to be tens of degrees lower than the reactor temperature ${ }^{31}$ because the heat released by the exothermic reactions (1)-(3) and (5) can cause significant and undesirable temperature gradients inside the reactors and result in catalyst deactivation. However, the temperature profiles are highly specific to the convective effects/cooling mechanisms employed in different reactor designs and hence in this study the inlet gas temperatures were matched to the reactor temperatures, resulting in slight overestimation of heater duties.

\section{Energy efficiency analysis}

There were three levels in the analyses of system energy requirements: in the first, the heater and compressor energy requirements were met entirely by external means and were associated with additional $\mathrm{CO}_{2}$ emissions; in the second, the pre-flash column heat exchangers were coupled with the recycle loop heat exchangers via a water stream to generate an energy saving; finally, combustion of the $\mathrm{H}_{2}$ and $\mathrm{CO}$ gases in the purge stream to meet a fraction of the compressor and heat exchanger energy requirements was considered as an option. The complete conversion of the purged $\mathrm{H}_{2}$ and $\mathrm{CO}$ to either heat or electrical energy was assumed to allow the utilisation of $c a .60 \%$ of the combustion energy, based on their respective lower heating values $\left(237 \mathrm{~kJ} \mathrm{~mol}^{-1}\right.$ for $\mathrm{H}_{2}$ and $283 \mathrm{~kJ} \mathrm{~mol}^{-1}$ for $\mathrm{CO}^{32}$ ). These additional considerations are shown schematically in Fig. 5.

\section{Compressors, pumps, heat exchangers and distillation columns}

The gas compressors were assumed to operate with an isentropic efficiency of $90 \%$ and a mechanical efficiency of $90 \%$. The water stream by which the heat exchangers were coupled had initial temperature and pressure of $20^{\circ} \mathrm{C}$ and 1 atmosphere respectively, and was pressurized with a pump assumed to operate with $70 \%$ energy efficiency to 40 bar prior to entry into the first heat exchanger. This water stream was constrained to a liquid state $\left(T_{\text {sat }}=250{ }^{\circ} \mathrm{C}\right.$ at 40 bar $)$ at all stages. Additional heat exchangers were added to the recycle loop to ensure the recycled gas stream was pre-heated to $250{ }^{\circ} \mathrm{C}$, prior to re-entry into the first reactor.

DSTWU distillation columns in Aspen Plus, utilising Gilliland's, Winn's, and Underwood's methods were used to model methanol separation from water by computing the required number of stages and reflux ratios for each scenario. Idealised separators were employed for removing $\mathrm{CO}_{2}$ and any minute fractions of $\mathrm{CO}$ and $\mathrm{H}_{2}$ from the liquid crude methanol stream prior to entry into the distillation units.

Not taken into account were the energy requirement and $\mathrm{CO}_{2}$ emissions associated with the supply of the air $/ \mathrm{O}_{2}$ that would be required to support $\mathrm{CO}$ and $\mathrm{H}_{2}$ combustion. Furthermore, the

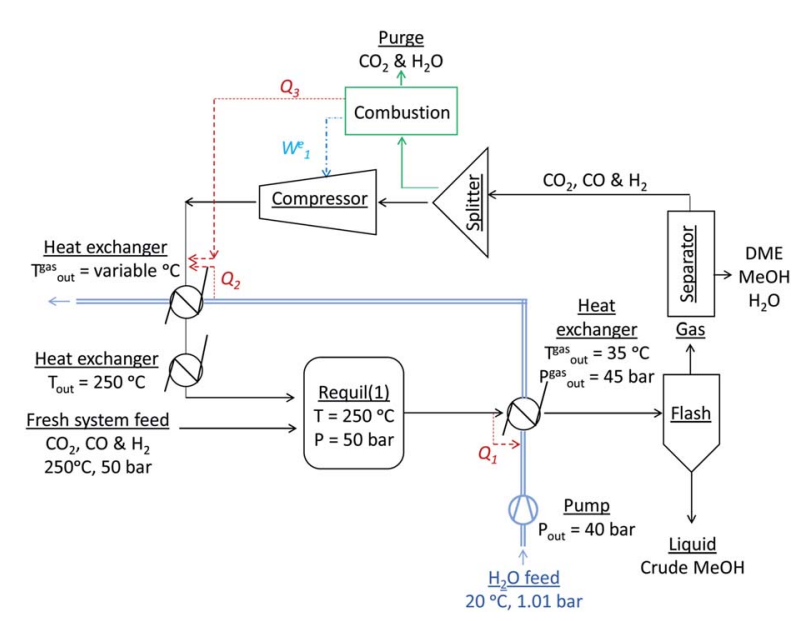

Fig. 5 Schematic illustration of the two simulated energy saving methods in a given recycle loop. In the first energy saving method, heat is recovered from the post-reactor gas stream by a cold pressurised water stream and subsequently delivered to the cold gas stream in the recycle loop. In the second energy saving method the purged $\mathrm{H}_{2}$ and $\mathrm{CO}$ gases are combusted and a fraction of the energy is recovered as heat and/or work and delivered to the heat exchanger and compressor, respectively, in the recycle loop. 
energy required to pressurise and heat the fresh feed gases to the system were not included and are part of a separate analysis that addresses the mechanisms of syngas production.

\section{$\mathrm{CO}_{2}$ emissions}

The power demand and $\mathrm{CO}_{2}$ emissions associated with the heat exchangers as well as with the compressors, the water pump and the reboiler and condenser in the distillation columns were computed and taken into account in the energy balance, assuming emissions of $5.4 \mathrm{~kg}\left(\mathrm{CO}_{2}\right) \mathrm{GJ}^{-1} \cdot{ }^{33}$ In practice, the gases can either undergo homogenous combustion, for which the combustion temperature would need to exceed the autoignition temperatures of both $\mathrm{H}_{2}\left(500{ }^{\circ} \mathrm{C}\right)$ and $\mathrm{CO}\left(609{ }^{\circ} \mathrm{C}\right)^{34}$ or alternatively direct conversion to electrical energy in fuel cells. $\mathrm{CO}_{2}$ emissions resulting from complete combustion of the purged $\mathrm{CO}$ have also been taken into account; combustion of $\mathrm{H}_{2}$ does not generate $\mathrm{CO}_{2}$ as the product is only water vapour.

\section{Results and discussion}

\section{Equilibrium yields without recycle}

Although calculations for equilibrium yields have been performed previously for both methanol and DME synthesis, ${ }^{25}$ and are conclusive about the optimum molar proportions of $\mathrm{H}_{2}$ and $\mathrm{CO}$ in the reactor feed, it is beneficial to perform these calculations with the additional inclusion of $\mathrm{CO}_{2}$ in order to understand the different choices of feed compositions used industrially, especially where $\mathrm{CO}_{2}$ is the principal source of carbon. Hence, initially the per-pass equilibrium yields of methanol and DME, their molar fractions in the reactor product streams, the extents of $\mathrm{H}_{2}, \mathrm{CO}_{2}$ and $\mathrm{CO}$ conversion, as well as the molar fractions of the water byproduct are shown in Fig. $1 \mathrm{~S}-4 \mathrm{~S}$ in the (ESI + ).

Fig. $1 \mathrm{~S}(\mathrm{a}) \dagger$ shows that in the case of methanol synthesis, the process output is much more sensitive to the $\mathrm{H}_{2}$ : $\mathrm{CO}$ ratio than it is to the $\mathrm{H}_{2}: \mathrm{CO}_{2}$ ratio. As shown previously, ${ }^{25}$ a process utilising principally $\mathrm{H}_{2}$ and $\mathrm{CO}$ in the feed exhibits optimum performance in terms of the methanol molar fraction in the product stream at the stoichiometric $\mathrm{H}_{2}: \mathrm{CO}$ ratio of $\approx 2$. At higher $\mathrm{H}_{2}$ to carbon ratios, the conversion of $\mathrm{CO}_{2}$ and $\mathrm{CO}$ to methanol continues to increase with a decreasing slope (subFig. 1S(c) and (d) $\dagger)$, but at the expense of lower hydrogen conversion (Fig. 1S(e) $\dagger$ ). Hence, the choice of whether to operate under hydrogen rich conditions will be dictated by the cost of hydrogen production and energy consumption of methanol separation. However, hydrogen-rich conditions can promote the formation of water, especially when $\mathrm{CO}_{2}$ is the main source of carbon, and this places significant constraints on the choice of catalyst. Water production by the reverse water gas shift reaction increases substantially with $\mathrm{CO}_{2}$ fraction in the syngas feed, passing through a maximum at $\mathrm{H}_{2}: \mathrm{CO}_{2}$ of approximately 2, but subsequently decreasing (Fig. $1 \mathrm{~S}(\mathrm{f}) \dagger$ ). The decay in the molar fraction of the water by-product under hydrogen rich conditions for a $\mathrm{H}_{2}-\mathrm{CO}_{2}$ feed justifies the choice of higher $\mathrm{H}_{2}: \mathrm{CO}_{2}$ ratios employed industrially. ${ }^{11,13}$ Consequently, for systems utilising primarily $\mathrm{CO}$ and $\mathrm{H}_{2}$, stoichiometric feed compositions give the optimum yield, while for systems using primarily $\mathrm{CO}_{2}$ and $\mathrm{H}_{2}$, higher $\mathrm{CO}_{2}$ conversion can be achieved under hydrogen-rich conditions, provided the hydrogen can be sourced sufficiently cheaply and the chosen catalyst can tolerate water build-up. However, even if $\mathrm{CO}_{2}$ is the sole source of carbon in the system feed, in the presence of a recycle loop, a certain quantity of carbon monoxide will be present in the reactor feed as it is formed via the reverse water gas shift reaction in parallel with methanol synthesis.

If methanol dehydration can proceed simultaneously with $\mathrm{CO}_{2}$ and $\mathrm{CO}$ hydrogenation, the methanol equivalent product (MEP) is greater than in the case of methanol, as shown in Fig. 6. The advantage is especially apparent when $\mathrm{H}_{2}:\left(\mathrm{CO}_{2}+\right.$ $\mathrm{CO})<1$. However, for the various $\mathrm{CO}_{2}$ : $\mathrm{CO}$ ratios it is apparent that the greatest advantage of the additional dehydration step can be gained when $\mathrm{CO}_{2}$ is the principal source of carbon. For a syngas feed without $\mathrm{CO}_{2}$, the maximum DME molar fraction in the product is found at a $\mathrm{H}_{2}$ : $\mathrm{CO}$ ratio of 1 , which corresponds to a more carbon rich regime relative to methanol alone (Fig. 2S(a)) in the (ESI + ). Under this condition, the build-up of water is minimised by the water gas shift reaction but at the expense of carbon dioxide formation, as is evident from Fig. $2 \mathrm{~S}(\mathrm{c}) . \dagger$ Hence, if the $\mathrm{CO}$ in the syngas is produced from $\mathrm{CO}_{2}$ in Stage 1 (Fig. 1), then it would be impractical to reverse the benefits of further conversion to fuel in Stage 2 by selecting conditions that would re-generate the $\mathrm{CO}_{2}$ to the greatest degree. Fig. 7 shows the extents of $\mathrm{CO}$ to $\mathrm{CO}_{2}$ conversion in the methanol and direct DME processes when a $\mathrm{H}_{2}$-CO only feed is used, illustrating the undesirable impact of the water gas shift process that takes place as a result of $\mathrm{H}_{2} \mathrm{O}$ formation from in situ methanol dehydration. Hence, operation with a $\mathrm{H}_{2}-\mathrm{CO}$ feed is unsuitable in the absence of $\mathrm{CO}_{2}$ recycle.

Unsurprisingly, the extents of $\mathrm{CO}$ and $\mathrm{H}_{2}$ conversion in direct DME synthesis also change very significantly relative to the case of methanol production; the increase in both is shown in Fig. $2 S(d)$ and (e). $\dagger$ Water build-up increases dramatically in

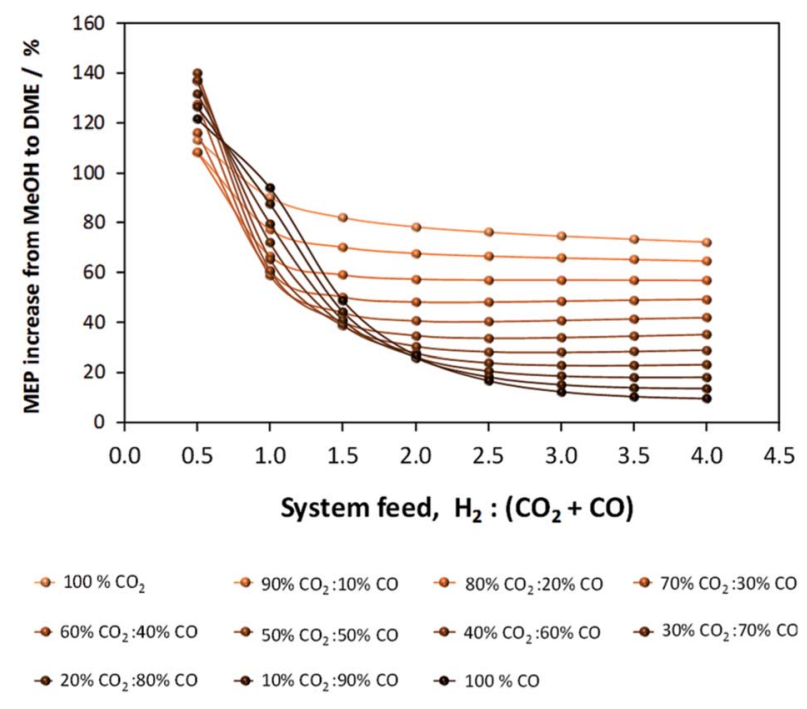

Fig. 6 MEP increase of the direct DME process relative to methanol alone; calculations based on reactor outputs at $250{ }^{\circ} \mathrm{C}$ and 50 bar in the absence of recycle. 


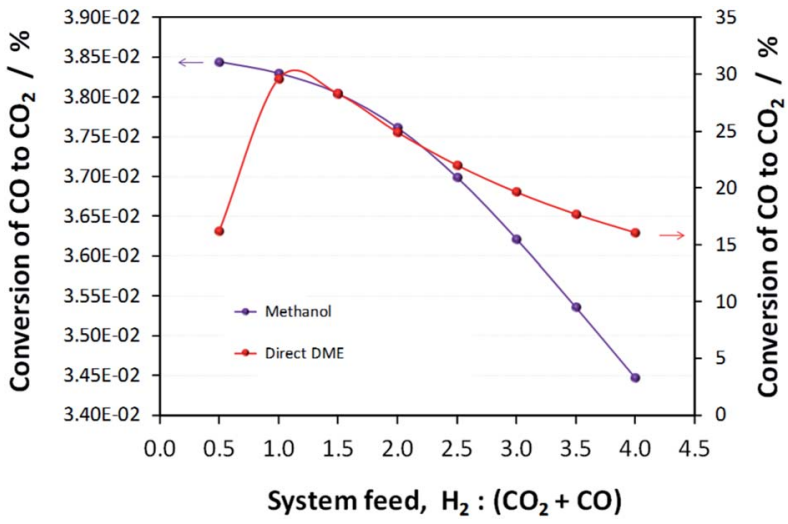

Fig. 7 Extents of $\mathrm{CO}$ conversion to $\mathrm{CO}_{2}$ via the water gas shift reaction during methanol and direct DME synthesis when a $\mathrm{H}_{2}-\mathrm{CO}$ only feed was employed.

the direct DME synthesis process relative to the methanol process (Fig. $2 \mathrm{~S}(\mathrm{f}) \dagger$ ) and this is thought to be the principal reason why the direct synthesis of DME is not yet deployed industrially. Once catalysts able to survive water build-up are developed then direct utilisation of $\mathrm{CO}_{2}$ rather than $\mathrm{CO}$ is preferable if the direct DME synthesis is to simultaneously fulfil the requirements of achieving net negative $\mathrm{CO}_{2}$ emissions and higher MEP relative to methanol synthesis alone.

Two principal disadvantages of direct DME synthesis, namely the net negative $\mathrm{CO}_{2}$ conversion over a wide range of syngas compositions and also the ultimate need to separate DME from $\mathrm{CO}_{2}$, which are strongly associating, can be overcome if the 2-step synthesis is employed. However, because the twostep process does not utilise the synergy between the $\mathrm{CO}_{2}$ and $\mathrm{CO}$ hydrogenation processes and the methanol dehydration process, the MEP will not improve relative to methanol synthesis alone. Fig. $3 \mathrm{~S}$ and $4 \mathrm{~S}$ in the ESI $\dagger$ show results corresponding to two possible scenarios for the two-step process: in the first scenario, the unreacted syngas $\left(\mathrm{H}_{2}, \mathrm{CO}_{2}\right.$ and $\left.\mathrm{CO}\right)$ from the methanol reactor is cooled and separated from the product stream in a condenser; the crude liquid methanol undergoes distillation and the isolated methanol stream then undergoes further processing in the DME reactor (Fig. $3 \mathrm{~S}^{\dagger}$ ). In the second scenario the product stream from the methanol reactor is fed directly into the DME reactor without any processing and it is assumed that only the methanol dehydration, unaccompanied by the WGS reaction, can occur in the second reactor (Fig. 4S); it was assumed explicitly that the rate of the WGS process is nil or negligible on methanol dehydration catalysts, for example when using $\gamma-\mathrm{Al}_{2} \mathrm{O}_{3}$ as catalyst at $250{ }^{\circ} \mathrm{C}$.

The principal conclusion from the comparison of the twostep systems is that in terms of thermodynamics, there is no added benefit in isolating the water and unreacted syngas from the methanol before it undergoes dehydration to DME in the second reactor. This is because at $250{ }^{\circ} \mathrm{C}$ the equilibrium yield of DME from methanol is virtually independent of pressure. Hence, although the partial pressure of methanol is much lower in the absence of a separation step, the conversion is not affected. But again, in reality the kinetics may be affected by the strong difference in partial pressure between the two systems. The DME yield was marginally lower in the 'separated' case due to the efficiency of liquid methanol separation in the condenser. In conclusion, the choice of process will depend on the relative energy demands of the extra distillation and re-heating steps in the separated case and with DME separation from $\mathrm{CO}_{2}$ in the non-separated case.

\section{Methanol and DME synthesis systems analysis}

Results presented in Fig. 6, 7 and $1 \mathrm{~S}-4 \mathrm{~S}$ in the ESI $\dagger$ differ dramatically once a recycle loop is introduced and energy demands for various different system components are accounted for. Fig. 8 shows the overall efficiencies for the methanol synthesis system for two extreme cases: (a) a $\mathrm{H}_{2}-\mathrm{CO}$ only feed and (b) a $\mathrm{H}_{2}-\mathrm{CO}_{2}$ only feed. Net energy outputs were computed as the energies extracted in the form of methanol and corrected by the energy demands for system operation and energies lost in unreacted $\mathrm{H}_{2}$ and $\mathrm{CO}$ gases that were vented. These outputs were normalised by the total energies contained in the $\mathrm{H}_{2}$ and $\mathrm{CO}$ feeds to the systems. Worst case scenarios in both cases correspond to situations where no energy saving mechanisms were employed; the best case (theoretical only) scenarios show only the energy contained in the methanol, assuming the syngas conversion systems require no additional energy to operate. Three intermediate cases show the net energy outputs when heat exchangers were coupled, when the vented gases were used for heat/power production and when both of these energy saving mechanisms were employed together. Fig. 8(c) and (d) show the corresponding contributions of these energy saving methods for the $\mathrm{H}_{2}-\mathrm{CO}$ and $\mathrm{H}_{2}-\mathrm{CO}_{2}$ scenarios.

Methanol production with a $\mathrm{H}_{2}-\mathrm{CO}$ only feed shows the predictable peak in performance at a system feed $\mathrm{H}_{2}$ : $\mathrm{CO}$ ratio of 2.0. At this ratio, the system requires minimal energy savings and the point of optimal performance is affected only marginally by the improvements to the energy efficiency. In terms of energy savings, across the entire $\mathrm{H}_{2}$ : $\mathrm{CO}$ range greater energy savings were obtained by combusting the vented unreacted $\mathrm{H}_{2}$ and $\mathrm{CO}_{2}$; hence this approach is essential.

In the absence of energy savings, the optimum operating point for the $\mathrm{H}_{2}-\mathrm{CO}_{2}$ system lies at a $\mathrm{H}_{2}: \mathrm{CO}_{2}$ ratio of 2.5, which, interestingly, is not the stoichiometric ratio of reaction (2). The peak, however, is much broader than in the $\mathrm{H}_{2}-\mathrm{CO}$ case and the acceptable operating range is arguably between $\mathrm{H}_{2}: \mathrm{CO}_{2}$ feed ratios of 2.0-3.0. The $\mathrm{H}_{2}: \mathrm{CO}_{2}$ ratio of highest net energy production remained unchanged regardless of which energy saving mechanisms were employed. The slopes of the curves are markedly different to those for the $\mathrm{H}_{2}-\mathrm{CO}$ case, especially at hydrogen-rich conditions, and show the greater tolerance of $\mathrm{H}_{2}-\mathrm{CO}_{2}$ system to different feed gas ratios.

The optimum operating range evident from Fig. $8 \mathrm{~b}$ is not in agreement with the preferred $\mathrm{H}_{2}: \mathrm{CO}_{2}$ feed ratios of 5.0 and 3.5, specified in ref. 11 and 13, respectively. It is possible that if hydrogen was sourced renewably, then limiting the $\mathrm{H}_{2}$ fraction in the feed was less important. The molar fractional water content in the reactor is only marginally lower at $\mathrm{H}_{2}: \mathrm{CO}_{2}$ of 3.5 $(0.058)$ than at $2.5(0.062)$ and so the reasons for the use of 


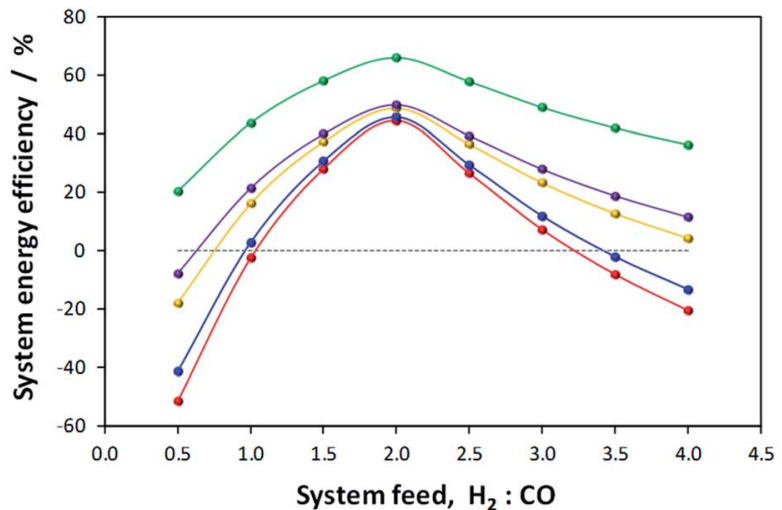

(a)

$$
\begin{aligned}
& \rightarrow \text { No energy savings } \\
& - \text { With gas combustion } \\
& \rightarrow \text { No losses }
\end{aligned}
$$

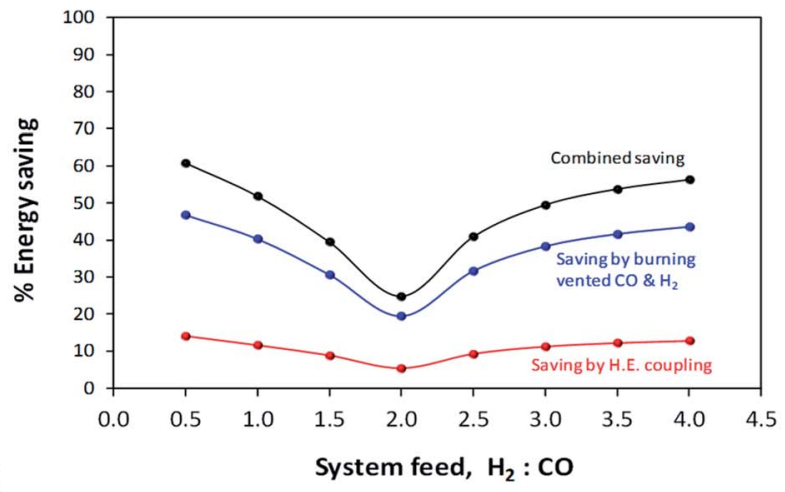

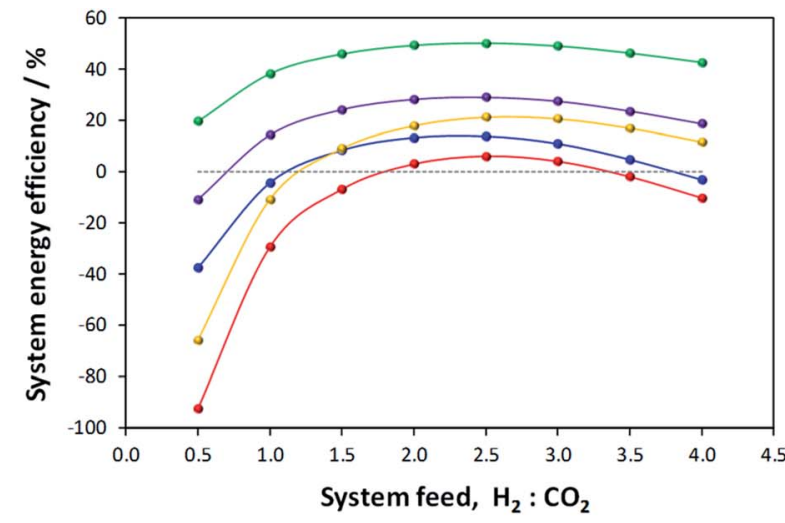

(b)

$\rightarrow$ With H.E. coupling
$\rightarrow$ With H.E. coupling and gas combustion

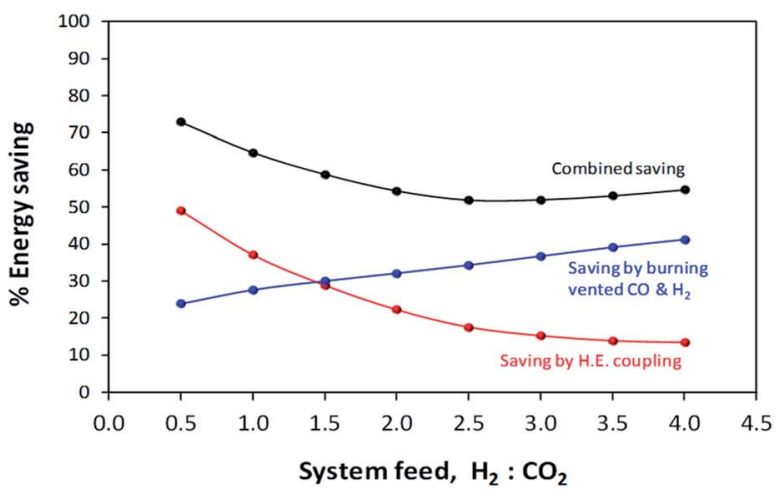

Fig. 8 Efficiencies for the methanol synthesis system for two extreme cases: (a) a $\mathrm{H}_{2}-\mathrm{CO}$ only feed and (b) a $\mathrm{H}_{2}-\mathrm{CO}_{2}$ only feed. The 'no losses' scenario is a theoretical-only case in which the syngas conversion process consumes no energy and vented gases do not constitute energy loss. The corresponding energy savings made by coupling heat exchangers and by combustion of vented gases are shown in (c) and (d).

higher $\mathrm{H}_{2}$ mole fractions are probably rather related to kinetics. Finally, Fig. 8b and (d) demonstrate that, for a $\mathrm{H}_{2}-\mathrm{CO}_{2}$ feed, both energy saving methods are necessary to achieve a positive net energy output and to improve the system efficiency.

Fig. $5 \mathrm{~S}$ in the ESI $\dagger$ shows the optimised net energy output curves for (a) the methanol, (b) direct DME, (c) 2-step DME synthesis with an interposed syngas separation step and (d) 2step DME synthesis with no separation step between the two reactors. For each scenario, curves for a $\mathrm{H}_{2}-\mathrm{CO}$ only, $\mathrm{H}_{2}-\mathrm{CO}_{2}$ only and $\mathrm{H}_{2}-\left(50 \% \mathrm{CO}: 50 \% \mathrm{CO}_{2}\right)$ system feeds are presented. In all the cases where methanol is produced in the first step, the optimum operating point lies between $\mathrm{H}_{2}$ : $\mathrm{C}$ ratios of 2.0-2.5, being higher for syngas system feeds with more $\mathrm{CO}_{2}$ content. The optimum point for the direct DME synthesis is at a ratio of 1.0 for the $\mathrm{H}_{2}-\mathrm{CO}$ case, but the breadth of the peak allows for high efficiency operation between ratios of 1.0-2.0. For the $\mathrm{H}_{2}-$ $\mathrm{CO}_{2}$ feed in the direct DME case the peak is again at the feed ratio of 2.5. Interestingly, the $50: 50 \mathrm{CO}_{2}: \mathrm{CO}$ cases exhibited considerably higher efficiencies at $\mathrm{CO}_{2} / \mathrm{CO}$-rich conditions compared with the other two feed compositions.

Table 1 shows the peak energy efficiencies that have been computed for each system both in the absence and presence of energy saving procedures. These maxima are evident in Fig. 9, where the net energies obtained in the four processes are compared directly. The highest efficiencies were obtained for $\mathrm{H}_{2}$-CO only feeds in the direct DME system and the 2-step DME system where there was no processing step between the two reactors. The poorer performance of the methanol system and the 2-step DME system in which crude methanol is isolated from the unreacted syngas and distilled before being dehydrated, is in part due to the poor efficiency of the methanol condensation stage. The fraction of the methanol extracted in liquid form is especially low under $\mathrm{CO} / \mathrm{CO}_{2}$-rich conditions, as shown in Fig. $6 \mathrm{~S}$ in the ESI. $\dagger$ The fraction of DME recovered from the flash column in gaseous form, however, is considerably higher at over $99.8 \%$ across the whole $\mathrm{H}_{2}$ : C range, as shown in Fig. 7S. $\uparrow$ Furthermore, the 2-step system with separation has additional energy demands for reheating and recompressing the methanol and for this reason exhibits the poorest performance.

It should be noted that the penalties in terms of the energy demands for DME recovery from syngas and the resultant decreases in efficiency were not included in the analysis. In practice, DME can be removed by exposure of the gaseous 
Table 1 The efficiencies of systems operating without and with maximum energy savings for three feed compositions: $100 \% \mathrm{CO}_{2}, 100 \% \mathrm{CO}$ and $50 \% \mathrm{CO}_{2}: 50 \% \mathrm{CO}$. The net energy outputs of each system were normalised against the energies contained in the $\mathrm{CO}$ and $\mathrm{H}_{2}$ gases in the system feeds

\begin{tabular}{|c|c|c|c|c|c|c|c|c|}
\hline System feed & \multicolumn{8}{|c|}{ Maximum energy efficiency/\% } \\
\hline $100 \% \mathrm{CO}$ & 44.6 & 63.3 & 34.6 & 60.4 & 49.9 & 69.2 & 44.6 & 65.7 \\
\hline & Difference & in energy & efficiency obtaine & with CO-only feeds a & ad $\mathrm{CO}_{2}$-only & feeds $/ \%$ & & \\
\hline & 38.5 & 23.9 & 37.0 & 43.0 & 21.0 & 16.2 & 20.2 & 25.2 \\
\hline
\end{tabular}

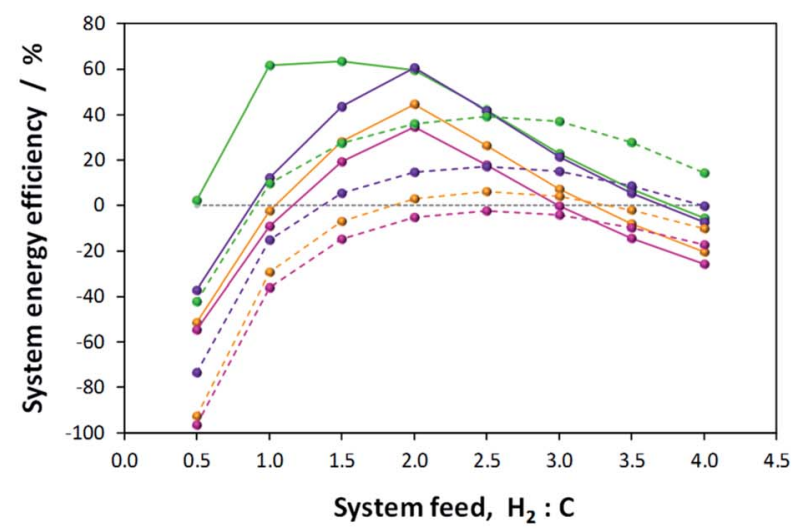

(a)

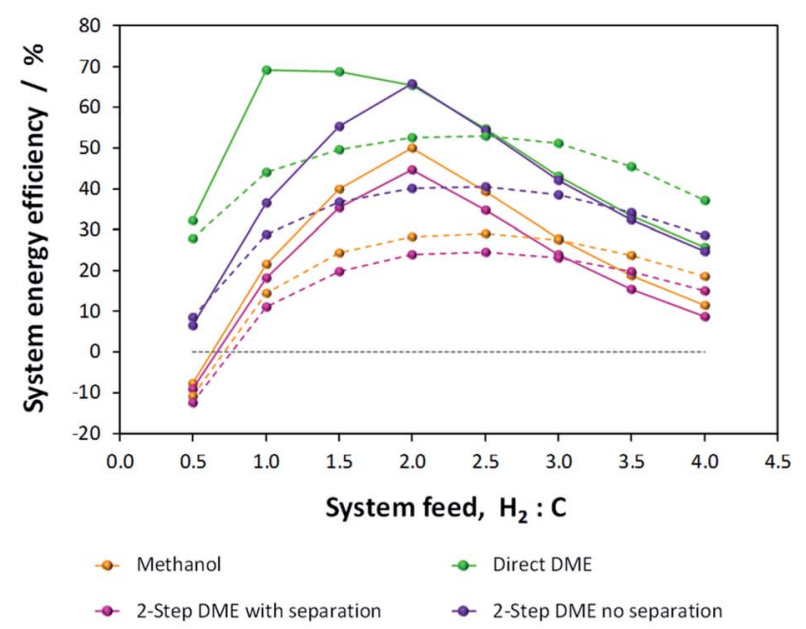

(b)

Fig. 9 Net energies obtained with (a) no energy savings and (b) maximum savings with the $\mathrm{H}_{2}-\mathrm{CO}$ only (solid lines) and $\mathrm{H}_{2}-\mathrm{CO}_{2}$ only (dashed lines) system feeds for the four systems under investigation.

output from the flash column to a water stream in which DME is soluble. ${ }^{23}$ The water scrubbing fluid would be at a temperature in the range $1-20{ }^{\circ} \mathrm{C}$ and at a similar pressure to that at which DME synthesis is carried out. Subsequently, DME could be separated from water at reduced pressure in a flash column.
The goal of the present study was to identify the best system for either directly processing $\mathrm{CO}_{2}$ or indirectly resulting in a positive net $\mathrm{CO}_{2}$ conversion. The best system for the direct conversion of $\mathrm{CO}_{2}$ will be the one for which the net energy output with a $\mathrm{H}_{2}-\mathrm{CO}_{2}$ only feed matches most closely the net energy output with a $\mathrm{H}_{2}-\mathrm{CO}$ only feed, as for each system the latter case always gives the highest syngas conversion. In the absence and presence of performance optimisation, the best direct utilisation for $\mathrm{CO}_{2}$ is in the direct DME process. Thermodynamic calculations show that at equilibrium conversion the difference in energy efficiencies between $\mathrm{H}_{2}-\mathrm{CO}$ and $\mathrm{H}_{2}-$ $\mathrm{CO}_{2}$ systems was $23.9 \%$ and $16.2 \%$, respectively. The peak efficiencies and corresponding differences between $\mathrm{H}_{2}-\mathrm{CO}$ and $\mathrm{H}_{2}-\mathrm{CO}_{2}$ cases were substantially greater for the other three systems.

In terms of performance, the next best system to 1-step DME was the two-step DME synthesis with direct transfer of methanol and unreacted syngas to the DME reactor. System analysis yielded considerably better results than for an analogous system in which crude methanol was separated from the unreacted syngas and distilled before being dehydrated to DME before. The latter suffered from the efficiency of liquid methanol extraction from the flash column and the extra energy requirements for reheating and recompressing concentrated methanol before the DME reactor. However, we again note that this difference is not likely to be reflected in the kinetics, which will be superior when methanol is not diluted by water or unreacted syngas; water especially would shift the equilibrium in reaction (5) unfavourably towards methanol. Furthermore, the 2-step DME system with an interposed methanol isolation stage could potentially have a higher overall energy conversion efficiency as it liberates the greatest amount of heat from methanol/DME syntheses, as shown in Fig. $8 \mathrm{~S}$ in the ESI, $\uparrow$ which would contribute to energy savings upstream.

A comparison of MEP values between the direct DME process and the methanol process in the presence of their respective recycle loops is presented in Fig. 10. When these curves are compared with those of Fig. 6 where a recycle loop was not employed, it is clear that the act of recycling alters the $\mathrm{H}_{2}$ : $\mathrm{CO}: \mathrm{CO}_{2}$ ratios relative to those in the system feed so as to 


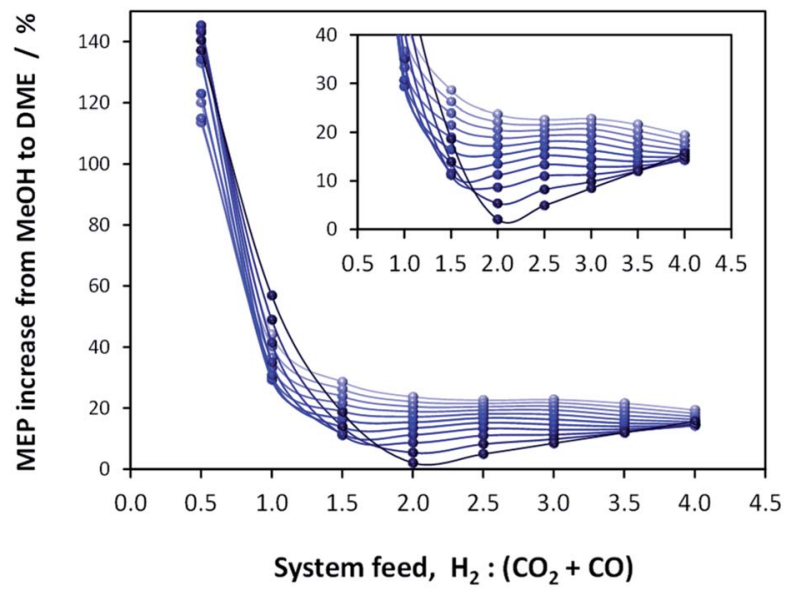

$$
\begin{aligned}
& -100 \% \mathrm{CO}_{2} \rightarrow 90 \% \mathrm{CO}_{2}: 10 \% \mathrm{CO} \rightarrow-80 \% \mathrm{CO}_{2}: 20 \% \mathrm{CO} \rightarrow 70 \% \mathrm{CO}_{2}: 30 \% \mathrm{CO} \\
& \rightarrow 60 \% \mathrm{CO}_{2}: 40 \% \mathrm{CO} \rightarrow 50 \% \mathrm{CO}_{2}: 50 \% \mathrm{CO} \rightarrow 40 \% \mathrm{CO}_{2}: 60 \% \mathrm{CO} \rightarrow 30 \% \mathrm{CO}_{2}: 70 \% \mathrm{CO} \\
& \rightarrow 20 \% \mathrm{CO}_{2}: 80 \% \mathrm{CO} \rightarrow 10 \% \mathrm{CO}_{2}: 90 \% \mathrm{CO} \rightarrow 100 \% \mathrm{CO}
\end{aligned}
$$

Fig. 10 MEP increase of the direct DME process relative to methanol alone; calculations based on system outputs (post flash separation and distillation processes etc.).

inhibit system performance for the direct DME case. This is due to the formation and build-up of $\mathrm{CO}_{2}$ via the water gas shift reaction between $\mathrm{CO}$ and the $\mathrm{H}_{2} \mathrm{O}$ that is formed during methanol dehydration. It is for this reason that such relatively high performance with $\mathrm{H}_{2}-\mathrm{CO}_{2}$ only feeds can be achieved. The large build-up of $\mathrm{CO}_{2}$ with a $\mathrm{H}_{2}-\mathrm{CO}$ feed in the direct DME process relative to the other systems is confirmed in Fig. 11, where the $\mathrm{CO}: \mathrm{CO}_{2}$ ratio in the recycle loop is in the range 0.625 , despite the ratio being 260000 in the system feed (we note that for a ' $\mathrm{H}_{2}$ : CO-only' system, a small molar fraction of $\mathrm{CO}_{2}$ was fed into the system together with $\mathrm{CO}$ in order to prevent excessive $\mathrm{CO}_{2}$ build-up). The differences in the ratios for the other systems are due to variances in the separation efficiencies of $\mathrm{CO}_{2}$ as gas in the flash column.

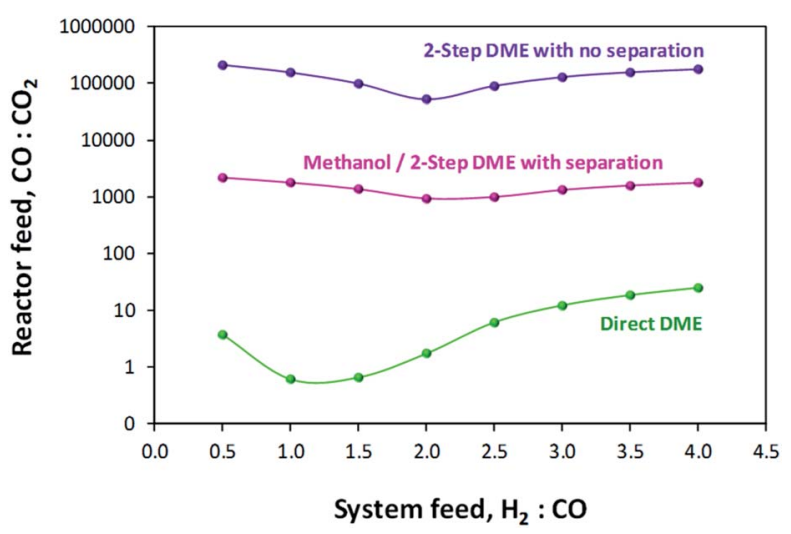

Fig. $11 \mathrm{CO}: \mathrm{CO}_{2}$ ratios in the recycle loops for the methanol/DME synthesis systems, fed only with $\mathrm{H}_{2}$ and $\mathrm{CO}$.
In principle, all or part of the $\mathrm{CO}_{2}$ in the recycle loop can be removed simultaneously with DME using a scrubbing solvent, such as a mixture of methanol and DME. ${ }^{28}$ However, subsequently several stages to separate the DME from the $\mathrm{CO}_{2}$ and also to recycle the scrubbing solvent will be required. The $\mathrm{CO}_{2}$ will also need to be recycled upstream of the reactor in order not to be emitted to the atmosphere. Alternatively, the $\mathrm{CO}_{2}$ and DME could be condensed out of the gaseous mixture. ${ }^{29}$ However, the combined $\mathrm{CO}_{2} / \mathrm{DME}$ removal and separation process will certainly result in a substantial efficiency penalty.

$\mathrm{CO}_{2}$ emissions were computed for the methanol/DME synthesis systems and included contributions from: $\mathrm{CO}_{2}$ emitted directly in the vented gases, additional $\mathrm{CO}_{2}$ emitted in the vented gases as a result of complete $\mathrm{CO}$ combustion in the energy saving scheme, $\mathrm{CO}_{2}$ contained in the crude methanol streams from the flash columns and $\mathrm{CO}_{2}$ emitted to power the process components, where the energy requirements were not met by the combustion of vented $\mathrm{CO}$ and $\mathrm{H}_{2}$. Results are shown in Fig. 12 and demonstrate that, unlike in the single pass scenario, $\mathrm{CO}_{2}$ emissions are minimal in the direct $\mathrm{DME}$ synthesis system.

Fig. 12 shows that the presence of a recycle loop minimised the emissions of $\mathrm{CO}_{2}$, which would otherwise have been very significant in the direct DME synthesis system operating with CO. In fact, $\mathrm{CO}_{2}$ emissions were greater for all systems utilising $\mathrm{H}_{2}-\mathrm{CO}_{2}$ only feeds due to the lower product yields (relative to $\mathrm{H}_{2}$-CO feeds) and the greater amounts of energy required to run the systems and maintain large amounts of unreacted gases in the recycle loops.

In summary, according to thermodynamic equilibrium calculations and system analysis, when $\mathrm{CO}_{2}$ is utilised as the principal source of carbon, the highest net energy outputs were achieved with the direct DME synthesis system. This system also demonstrated the highest overall performance with CO, albeit the MEP is reduced significantly by the large build-up of

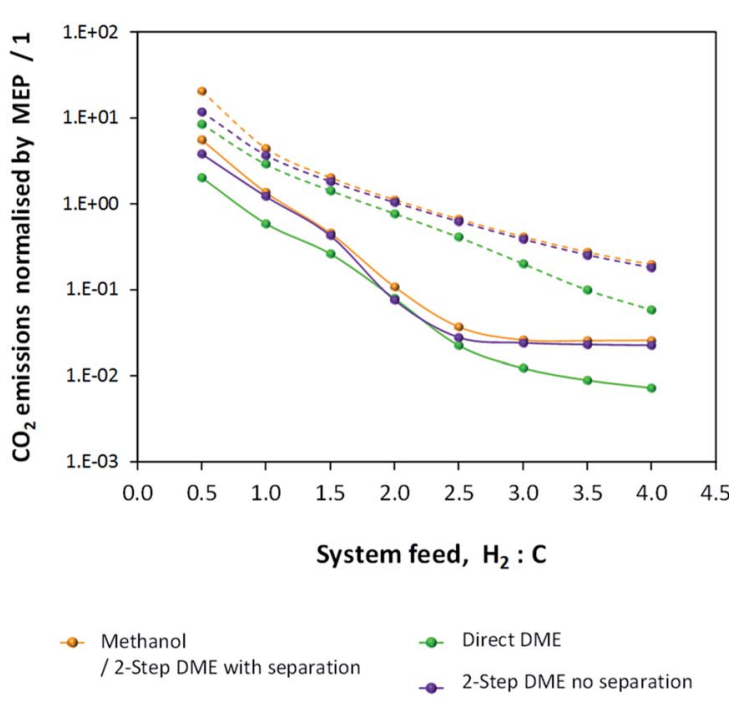

Fig. $12 \mathrm{CO}_{2}$ emissions normalised by the MEP for the methanol/DME production systems employing $\mathrm{H}_{2}-\mathrm{CO}$ only (solid lines) and $\mathrm{H}_{2}-\mathrm{CO}_{2}$ only (dashed lines) feeds. 
$\mathrm{CO}_{2}$ in the recycle loop due the water gas shift reaction between $\mathrm{CO}$ and the water generated by in situ methanol dehydration. Performance with $\mathrm{CO}_{2}$ as the carbon source can theoretically be lower than the performance with CO by only $16.2 \%$, provided energy saving strategies such as coupling of heat exchangers and the combustion of vented $\mathrm{CO}$ and $\mathrm{H}_{2}$ to generate thermal and electrical energies are employed. Hence, direct utilisation of $\mathrm{CO}_{2}$ is preferable in the direct DME system rather than in systems producing only methanol in the first stage. This system also achieves the highest degree of $\mathrm{CO}_{2}$ conversion.

Conversion of $\mathrm{CO}_{2}$ to $\mathrm{CO}$ upstream of the DME system that appears necessary for systems where methanol is produced in the first stage, would not be beneficial if the increase in the net energy yields are balanced or even outweighed by the energy requirements of this additional step. Upstream syngas production needs to be analysed with two points in mind. Firstly, based on the findings in this study, direct utilisation of $\mathrm{CO}_{2}$ requires at least 1.25 times more hydrogen in the system feed than when CO is used and this would result in additional penalties both in terms of energy requirement and $\mathrm{CO}_{2}$ emissions. Secondly, the heat liberated by reactions (1)-(3) and (5) in the methanol/DME reactors, and extracted in order to maintain isothermal conditions can be recovered and used to support upstream processes for generating $\mathrm{H}_{2}$ and $\mathrm{CO}$ from $\mathrm{H}_{2} \mathrm{O}$ and $\mathrm{CO}_{2}$. Fig. $8 \mathrm{~S}$ in the ESI $\dagger$ shows the heats liberated in the methanol and DME synthesis reactors under consideration in this study. More heat is liberated by $\mathrm{CO}$ dehydration than by $\mathrm{CO}_{2}$ dehydration. Hence, again, the benefits of a $\mathrm{H}_{2}-\mathrm{CO}$ only syngas could potentially be reversed if the upstream processes for converting $\mathrm{CO}_{2}$ and $\mathrm{H}_{2} \mathrm{O}$ to $\mathrm{CO}$ and $\mathrm{H}_{2}$ require substantially greater energy inputs than energy recoverable from the downstream reaction heat.

Hence, the criterion for directing the decision of whether to use $\mathrm{CO}_{2}$ or $\mathrm{CO}$ (produced upstream from $\mathrm{CO}_{2}$ ) as the principal sources of carbon in the feed for methanol/DME syntheses is that the value of 'net energy gain from using $\mathrm{CO}$ instead of $\mathrm{CO}_{2}$ in methanol/DME syntheses' is greater than the 'energy required to generate syngas of the required composition', with account taken for heat recoverable from downstream exothermic processes. An additional criterion is that the $\mathrm{CO}_{2}$ liberated to support the running of the systems must be only a small fraction of the $\mathrm{CO}_{2}$ utilised. Naturally, the decision would also be dictated by availability of catalysts able to support direct $\mathrm{CO}_{2}$ conversion to methanol, although as evidenced from ref. 11-13 this can already be carried out at industrial scale.

\section{Syngas production from $\mathrm{CO}_{2}$ and $\mathrm{H}_{2} \mathrm{O}$}

With decontaminated $\mathrm{H}_{2} \mathrm{O}$ and $\mathrm{CO}_{2}$ as the building blocks, syngas may be produced electrochemically and/or via the WGS/ RWGS reactions (3) using a variety of means depicted in Fig. 13. Hydrogen may be generated by the reduction of water in an electrolyser via reaction (11). The most commonly used device on an industrial scale is an alkaline electrolyser, which is typically operated at elevated temperatures in the range $60-90{ }^{\circ} \mathrm{C}$ and can also be performed at pressures up to 700 bar. Usually these devices operate with an energy efficiency of up to $70 \%$ and a faradaic efficiency close to unity.

$$
2 \mathrm{H}_{2} \mathrm{O}+2 \mathrm{e}^{-} \rightleftarrows \mathrm{H}_{2}+2 \mathrm{OH}^{-}
$$

A typical specific electrical energy consumption for alkaline water electrolysis at atmospheric pressure and at $75{ }^{\circ} \mathrm{C}$ without account of parasitic energy losses or gas losses is $c a .4 .5 \mathrm{~kW} \mathrm{~h}$ $\mathrm{Nm}\left(\mathrm{H}_{2}\right)^{-3} \approx 100 \mathrm{~kW} \mathrm{~h} \mathrm{kmol}\left(\mathrm{H}_{2}\right)^{-1} \cdot{ }^{35}$

Hydrogen produced by electrolysis may be utilised directly as shown in schemes (a)-(c) and (e) in Fig. 13 and/or reacted with $\mathrm{CO}_{2}$ via the RWGS process shown in (b) to generate a mixture of $\mathrm{CO}, \mathrm{H}_{2} \mathrm{O}, \mathrm{CO}_{2}$ and $\mathrm{H}_{2}$, from which $\mathrm{CO}$ and $\mathrm{H}_{2}$ can then be isolated and fed into the methanol/DME reactors. Schemes (a), in which a $\mathrm{CO}_{2}$-based syngas is generated, and (b), in which a CO-based syngas is generated, are based on readily available technologies with well-characterised performance.

In an alternative scheme to (b), CO may be produced directly by $\mathrm{CO}_{2}$ reduction using a technology that is still currently in the research phase: solid oxide electrolysis. ${ }^{36}$ During the reduction reaction (12), $\mathrm{CO}_{2}$ is split into $\mathrm{CO}$ and oxide ions; the oxide ions migrate across a solid oxide electrolyte and become oxidised to oxygen gas. The net system reaction is shown in eqn (13). This process takes place at elevated temperatures (typically 500-800 ${ }^{\circ} \mathrm{C}$ ), which are required to achieve a sufficient conductivity in the solid oxide electrolyte. CO produced in this way may be reacted directly with $\mathrm{H}_{2}$ to form methanol/DME etc., as shown in scheme (c) or reacted with water vapour via the WGS process to generate a mixture of $\mathrm{H}_{2}, \mathrm{CO}_{2}, \mathrm{H}_{2} \mathrm{O}$ and $\mathrm{CO}$, as shown in scheme (f). Although this technology is still very much under development, $\mathrm{CO}_{2}$ electrolysis in solid oxide systems is already being carried out industrially, for example by Haldor Topose. ${ }^{37}$

$$
\begin{gathered}
\mathrm{CO}_{2}+2 \mathrm{e}^{-} \rightleftarrows \mathrm{CO}+\mathrm{O}^{2-} \\
2 \mathrm{CO}_{2} \rightleftarrows 2 \mathrm{CO}+\mathrm{O}_{2}
\end{gathered}
$$

The specific electrical energy consumption for the production of $\mathrm{CO}$ via high temperature electrolysis of $\mathrm{CO}_{2}$ is reported to be of order $2.1 \mathrm{~kW} \mathrm{~h} \mathrm{~kg}\left(\mathrm{CO}_{2}\right)^{-1}$ (ref. 36) at $800{ }^{\circ} \mathrm{C}$ and $1 \mathrm{~atm}$., corresponding to $\approx 92 \mathrm{~kW} \mathrm{~h} \mathrm{kmol}(\mathrm{CO})^{-1}$.

High temperature $\mathrm{CO}_{2}$ electrolysis is reported to be more efficient if it is carried out simultaneously with the reduction of steam as per reaction (14), in a process termed co-electrolysis. ${ }^{38}$ This process has two principal advantages over the scheme in (13) firstly because $\mathrm{CO}_{2}$ reduction is aided by the RWGS process that takes place as $\mathrm{H}_{2}$ is formed and secondly because it suppresses the formation of solid carbon.

$$
\mathrm{CO}_{2}+\nu \mathrm{H}_{2} \mathrm{O} \rightleftarrows \mathrm{CO}+\nu \mathrm{H}_{2}+\frac{(1+\nu)}{2} \mathrm{O}_{2}
$$

The $\mathrm{H}_{2}$ : CO ratio in the resultant syngas is controlled by the $\mathrm{H}_{2} \mathrm{O}: \mathrm{CO}_{2}$ ratio in the feed. ${ }^{39}$ For example, the specific electrical energy consumption for co-electrolysis at $800{ }^{\circ} \mathrm{C}$ and $1 \mathrm{~atm}$. generating syngas with a molar ratio of $\mathrm{H}_{2}: \mathrm{CO}=2.0$ is estimated at $3.2 \mathrm{~kW} \mathrm{~h} \mathrm{\textrm {Nm } _ { \text { syngas } }}{ }^{-3}$. Co-electrolysis can be used as a standalone process to generate $\mathrm{a}_{2}-\mathrm{CO}$ syngas as shown in 


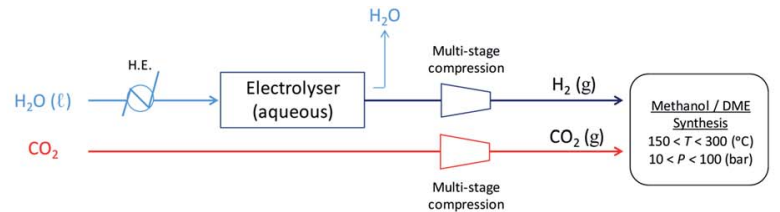

(a)

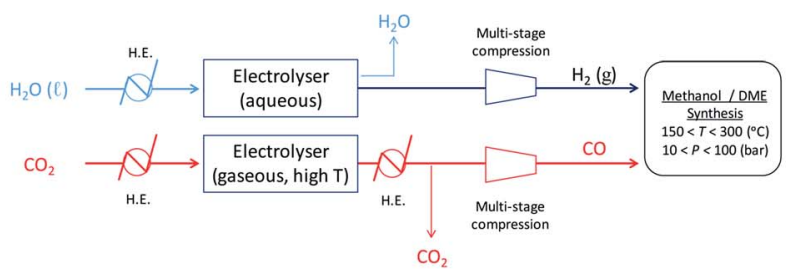

(c)

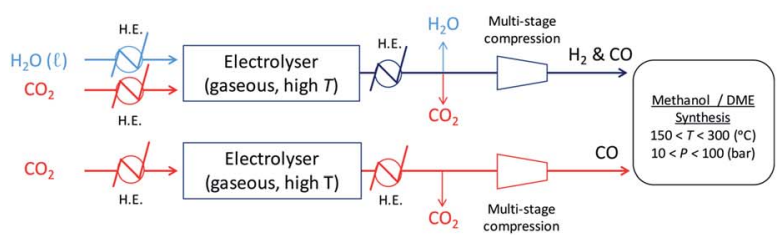

(e)

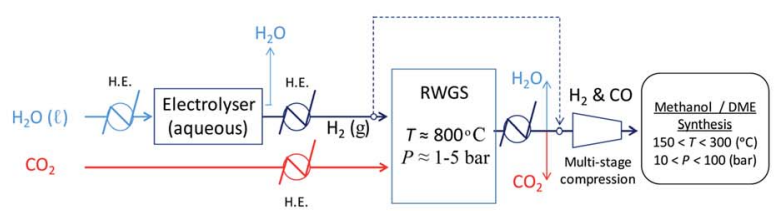

(b)

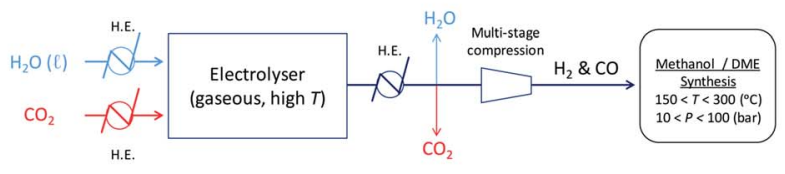

(d)

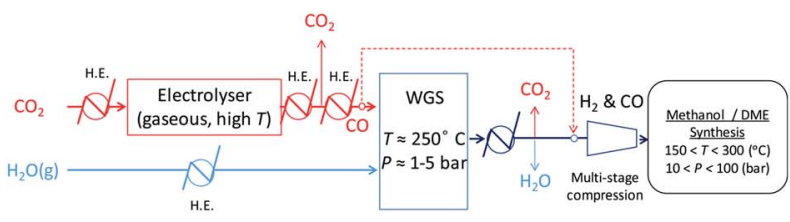

(f)

Fig. 13 Possible routes for the production of syngas, with varying ratios of $\mathrm{H}_{2}: \mathrm{C}$, from $\mathrm{H}_{2} \mathrm{O}$ and $\mathrm{CO}_{2}$.

scheme (d), or performed in parallel with $\mathrm{CO}_{2}$ electrolysis as in scheme (e) if the $\mathrm{H}_{2}-\mathrm{CO}$ ratio requires adjustment.

The energy requirements of schemes (a)-(f) in Fig. 13 were evaluated based on the specific electrical energy consumptions for alkaline electrolysis $\left(75^{\circ} \mathrm{C}, 1 \mathrm{~atm}\right.$.), $\mathrm{CO}_{2}$ electrolysis $\left(800^{\circ} \mathrm{C}\right.$, $1 \mathrm{~atm}$.) and $\mathrm{CO}_{2}-\mathrm{H}_{2} \mathrm{O}$ co-electrolysis $\left(800^{\circ} \mathrm{C}, 1 \mathrm{~atm}\right.$.) specified in

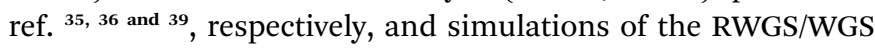
processes, as well as energy demands of heat exchangers and compressors relevant to each scheme, in Aspen Plus V8.8.

Stage 1 energy consumptions were used to determine the differences between normalised energies required to produce $\mathrm{CO}_{2}$-based syngas (scheme in Fig. 13a) with the optimum $\mathrm{H}_{2}$ : $\mathrm{CO}_{2}$ ratio of 2.5 for both methanol and DME syntheses and CO-based syngas with $\mathrm{H}_{2}$ : CO ratios of 2 and 1 for methanol and direct DME processes, respectively (schemes (b)-(f)). These differences are shown in Fig. 14, where they are compared with the normalised energy gains in Stage 2 that were achieved when a CO-based rather than $\mathrm{CO}_{2}$-based syngas was used in the production of methanol (Fig. 14a) and DME by the direct process (Fig. 14b). Results show that in the case of methanol synthesis, the benefits of a CO-based feed in Stage 2 always outweigh any additional energy requirements in Stage 1, regardless of which syngas production scheme was employed. Furthermore, when schemes (c) and (e) were used to produce CO-based syngas, less energy was consumed than in the production of hydrogen in scheme (a). Scheme (e) appears to be the best for producing syngas with the correct ratios for both methanol and DME synthesis, although it should be noted that the specific electrical energy consumption used in assessment of schemes (d) and (e) $)^{39}$ was not determined experimentally, unlike in the other schemes. Hence, further validation may be necessary. In the case of DME production, scheme (b) generated the worst case scenario, which showed that losses in Stage 1 were greater than gains in Stage 2 .

As well as energy consumption, the combined $\mathrm{CO}_{2}$ utilisation/emissions associated with Stages 1 and 2 are of critical importance in identifying the best system for $\mathrm{CO}_{2}$ conversion to fuels. The $\mathrm{CO}_{2}$ consumed (by conversion to $\mathrm{CO}$ ) and liberated (to support process energy demands) was computed for each Stage 1 scheme in Fig. 13; the net differences were normalised against the energies contained in the final syngas products, as shown in eqn (15). This enabled the comparison of net $\mathrm{CO}_{2}$ consumption in Stage 1 (negative for schemes (b)-(f) and positive for scheme (a)) with $\mathrm{CO}_{2}$ emissions in Stage 2, evaluated using eqn (16).

$$
\begin{gathered}
\text { Stage 1: } \mathrm{CO}_{2 \text { (emitted) }}=\frac{\mathrm{CO}_{2 \text { (emitted) }}-\mathrm{CO}_{2 \text { (consumed) }}}{\left(E_{\text {syngas }}\right)_{\text {out }}} \\
\text { Stage 2: } \mathrm{CO}_{2 \text { (utilised) }}=\frac{\mathrm{CO}_{2 \text { (vented })}-\mathrm{CO}_{2(\text { in })}}{\left(E_{\text {syngas }}\right)_{\text {in }}}
\end{gathered}
$$

When $\mathrm{CO}_{2}$ was converted to $\mathrm{CO}$ upstream of the methanol/ DME reactors (schemes (b)-(f) in Fig. 13), net $\mathrm{CO}_{2}$ utilisation was achieved in Stage 1, whereas direct use of $\mathrm{CO}_{2}$ in the methanol/DME reactors (scheme (a)) resulted in net $\mathrm{CO}_{2}$ utilisation in Stage 2. Fig. 15 shows a comparison of the relative $\mathrm{CO}_{2}$ utilisation and emissions, both normalised by the energy contained in the syngas, in Stages 1 and 2 of systems producing methanol and DME via the direct process. The direct DME 


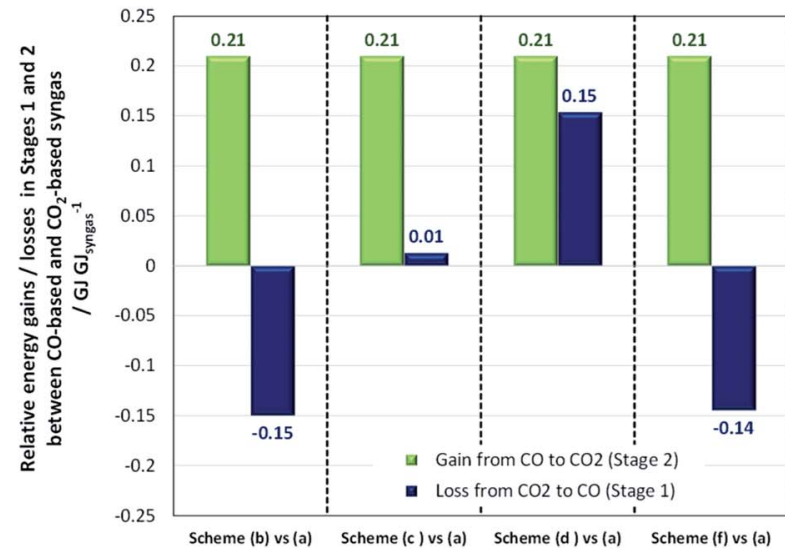

(a)

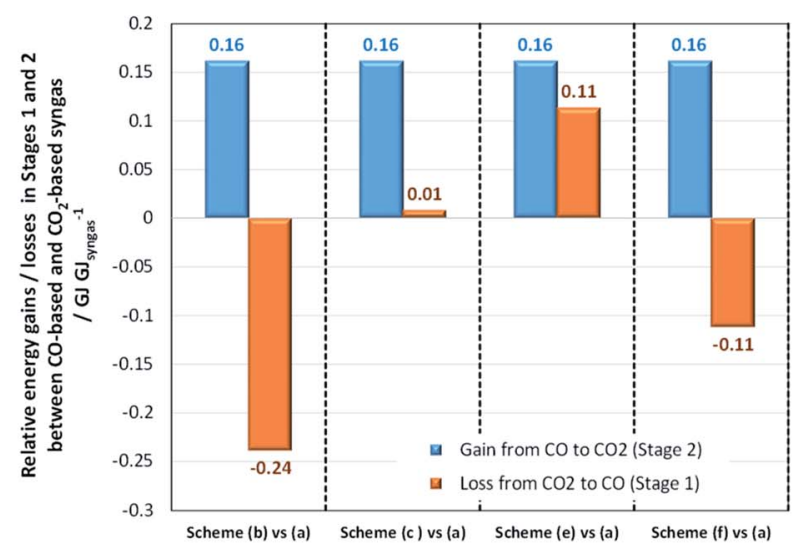

(b)

Fig. 14 Relative normalised energy losses in Stage 1 and gains in Stage 2 when (a) methanol and (b) direct DME systems are operated with $\mathrm{CO}$-based and $\mathrm{CO}_{2}$-based syngas.

process was modelled to utilise $\mathrm{CO}_{2}$-based syngas directly (produced in scheme (a) in Fig. 13) with the optimum $\mathrm{H}_{2}: \mathrm{CO}_{2}$ ratio of 2.5 identified earlier and also $\mathrm{CO}$-based syngas produced in schemes (b), (c), (e) and (f) with $\mathrm{H}_{2}: \mathrm{CO}=1$. Due to the poor performance of the methanol and 2-step DME systems with $\mathrm{CO}_{2}$ in the feed, the methanol system was modelled with a CO-based syngas only, using schemes (b), (c), (d) and (f) with $\mathrm{H}_{2}: \mathrm{CO}=2$.

The results presented in Fig. 15 show that while the production of syngas with $\mathrm{H}_{2}$ : CO ratio of 1 in Stage 1, tailored for direct DME synthesis, leads to the highest $\mathrm{CO}_{2}$ utilisation, the benefits are offset substantially by the generation of $\mathrm{CO}_{2}$ by the water gas shift reaction in Stage 2. For all the schemes considered, it has been calculated that between $50-54 \%$ of $\mathrm{CO}_{2}$ consumed in Stage 1 is regenerated in Stage 2. The extent of $\mathrm{CO}_{2}$ regeneration is reduced to $48 \%$ if direct DME synthesis is performed with $\mathrm{CO}_{2}$ rather than $\mathrm{CO}$, thereby confirming that direct utilisation of $\mathrm{CO}_{2}$ is possible and thermodynamically preferable with this process.

Results in Fig. 15 show unambiguously that if $\mathrm{CO}_{2}$ is converted to $\mathrm{CO}$ in Stage 1, then it is substantially better to use this $\mathrm{CO}$ for the production of methanol (or DME via the two-step routes) rather than DME via the direct route.

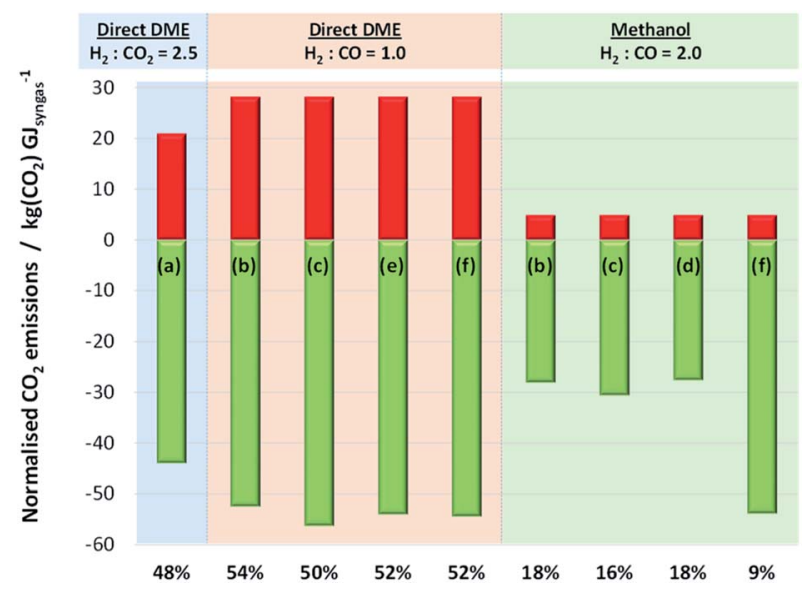

Fig. 15 Relative $\mathrm{CO}_{2}$ emissions and $\mathrm{CO}_{2}$ utilisation occurring in Stages 1 and 2 of systems for the production of methanol and direct DME. Negative $\mathrm{CO}_{2}$ emissions (green) represent net $\mathrm{CO}_{2}$ utilisation occurring in Stage 1 for schemes (b)-(f) in Fig. 13 and in Stage 2 for scheme (a). Conversely, positive $\mathrm{CO}_{2}$ emissions (red) represent $\mathrm{CO}_{2}$ liberated in Stage 2 for schemes (b)-(f) (due to WGS reaction) and in Stage 1 for scheme (a). Percentage values indicate the proportion of consumed $\mathrm{CO}_{2}$ that is re-emitted. Direct $\mathrm{CO}_{2}$ utilisation is modelled in the direct DME process, requiring syngas with $\mathrm{H}_{2}: \mathrm{CO}_{2}=2.5$ produced in scheme (a). The remaining schemes convert $\mathrm{CO}_{2}$ to $\mathrm{CO}$ in Stage 1, generating syngas with $\mathrm{H}_{2}: \mathrm{CO}=2$ for methanol production and $\mathrm{H}_{2}: \mathrm{CO}=1$ for DME production via the direct process in Stage 2 .

The conversion of $\mathrm{CO}_{2}$ to $\mathrm{CO}$ via high temperature electrolysis, followed by the WGS reaction with $\mathrm{H}_{2} \mathrm{O}$ (scheme (f) with $\mathrm{H}_{2}$ : CO $=2$ in the final syngas product) resulted in the highest degree of $\mathrm{CO}_{2}$ utilisation, with only $9 \%$ regenerated in Stage 2 . The better performance of the system in scheme (f) is principally due to the exothermic nature of the WGS reaction which reduces the energy requirements in Stage 1. There was no significant difference between the performances of methanol systems with schemes (b), (c) or (d) in Stage 1. We note that additional energy requirements associated with cooling the WGS reactor have not been considered; these and other subordinate elements were beyond the scope of the present estimations. Nonetheless, Fig. 9S in the ESI $\uparrow$ shows the energies released as heat (by exothermic reactions in Stage 2 processes such as WGS and by heat exchangers in Stage 1) relative to energy demands in Stage 1 for each scenario presented in Fig. 15; a fraction of the energy released as heat could be harnessed and used to decrease the energy consumption in Stage 1. However, conclusions based on the results in Fig. 15 are unlikely to be altered by these potential savings.

Based on results in Fig. 14 and 15 it can be concluded that in terms of energetic benefits and $\mathrm{CO}_{2}$ utilisation, methanol is best synthesised from CO-based syngas that is produced upstream using high temperature electrolysers or a combination of high temperature $\mathrm{CO}_{2}$ electrolysis coupled with a WGS system. On the other hand, the direct DME process can utilise $\mathrm{CO}_{2}$ directly; alternatively it can utilise syngas produced using the same methods as those identified for the case of methanol. In the cases of both methanol and direct DME syntheses, syngas production by a combination of an alkaline water electrolyser and a RWGS system yielded least favourable results. 
In all cases, greater flexibility with the design of Stage 1 systems will be afforded when renewable sources of energy are available. For example, in the case of CRI, ${ }^{\mathbf{1 2 , 4 0}}$ geothermal energy sources provide steam, which is used for generating electrical energy and for heating purposes. Alternatively solar energy could be used to generate electricity via photovoltaic devices, subject to location.

Although the supply of carbon dioxide is often seen as unlimited due to the vast quantities in which it is generated by industrial processes, its capture and purification are associated with significant energy demands and hence already at this initial stage, a fraction of the $\mathrm{CO}_{2}$ recovered is released into the atmosphere; ${ }^{41}$ this factor will ultimately be important in life cycle analyses on the methanol and DME synthesis systems that utilise $\mathrm{CO}_{2}$ as the sole source of carbon. However, in this study, the source of $\mathrm{CO}_{2}$ and the energy associated with its recovery and purification were not considered as it was not a factor affecting system comparisons; $\mathrm{CO}_{2}$ of similar purity is required, regardless of whether it is first converted to $\mathrm{CO}$ or fed into methanol/DME reactors directly. For example, to avoid problems associated with sulphur poisoning, the sulphur content in the syngas for the commonly employed Cu-based methanol/ DME catalysts needs to be below circa 1 ppm (ref. 7) and, likewise, below circa 5 ppm for the nickel/iron/cobalt catalysts used typically in solid oxide electrolysers. ${ }^{42}$

\section{Conclusions}

The key question in this study was whether $\mathrm{CO}_{2}$ could be fed directly to methanol/DME synthesis systems or whether its upstream conversion to $\mathrm{CO}$ was necessary. Hence, system efficiencies and extents of $\mathrm{CO}_{2}$ conversion were examined in four methanol/DME synthesis systems as a function of hydrogen to total carbon molar ratios, $\mathrm{H}_{2}:\left(\mathrm{CO}_{2}+\mathrm{CO}\right)$, as well as $\mathrm{CO}_{2}: \mathrm{CO}$ ratios, in the system feed. Recycle of unreacted $\mathrm{CO}_{2}$, as well as $\mathrm{H}_{2}$ and $\mathrm{CO}$, was enabled to minimise $\mathrm{CO}_{2}$ emissions. Energy requirements for the operation of heat exchangers, compressors and distillation columns, as well as energy saving strategies such as the coupling of heat exchangers and also the utilisation of energy generated by combustion of vented gases, were included in system assessment. Highest system efficiencies for the methanol, direct DME and two-step DME synthesis systems were obtained at a non-stoichiometric $\mathrm{H}_{2}: \mathrm{CO}_{2}$ ratio of 2.5 in the system feeds in the absence of upstream $\mathrm{CO}$ generation. For CO-based syngas, the highest efficiencies for the methanol/twostep DME and direct DME synthesis systems were obtained at stoichiometric $\mathrm{H}_{2}$ : CO feed ratios of 2 and 1, respectively. Direct utilisation of $\mathrm{CO}_{2}$ required maximum energy savings.

Taking account of energy requirements and $\mathrm{CO}_{2}$ emissions associated with the upstream syngas production stage, it was determined that $\mathrm{CO}_{2}$ could be utilised directly in the direct DME synthesis route, whereas upstream conversion of $\mathrm{CO}_{2}$ to CO was necessary to achieve significant yields and increased overall $\mathrm{CO}_{2}$ conversion with the methanol/two-step DME systems.

CO-based syngas production via high temperature coelectrolysis of $\mathrm{H}_{2} \mathrm{O}$ and $\mathrm{CO}_{2}$, or alternatively high temperature
$\mathrm{CO}_{2}$ electrolysis coupled with the WGS process, were identified as the best technologies based on energy consumption and $\mathrm{CO}_{2}$ conversion.

\section{Acknowledgements}

The authors thank the UK Engineering and Physical Sciences Research Council (EPSRC) for the post-doctoral research associateship for $\mathrm{AH}$ (grant EP/K035274/1). As per EPSRC requirements, we have made our experimental data available via Zenodo.org. The link to the data is: https://zenodo.org/record/ 817412\#.WUzky-vyvcs. It is also possible to access the data by entering the manuscript title into the search bar in http:// www.zenodo.org.

\section{References}

1 A. Goeppert, M. Czaun, J. P. Jones, G. K. S. Prakash and G. A. Olah, Chem. Soc. Rev., 2014, 43, 7995.

2 IPCC, IPCC Guidelines for National Greenhouse Gas Inventories, Prepared by the National Greenhouse Gas Inventories Programme, ed. H. S. Eggleston, L. Buendia, K. Miwa, T. Ngara and K. Tanabe, IGES, Japan, 2006.

$3 \mathrm{EU}$, Roadmap for moving to a low-carbon economy in 2050, European Commission, Brussels, Belgium, 2011, Short version, http://eur-lex.europa.eu/legal-content/EN/ALL/? uri=CELEX:52011DC0112, accessed in 03/2017.

4 EU, Roadmap 2050: a practical guide to a prosperous, lowcarbon Europe - Technical \& economic analysis (full report), European Climate Foundation, 2010, http:// www.roadmap2050.eu/reports, accessed in 03/2017.

5 G. A. Olah, A. Goeppert and G. K. S. Prakash, Beyond Oil and Gas: The Methanol Economy, Wiley-VCH, Weinheim, Germany, 2nd edn, 2009.

6 G. A. Olah, A. Goeppert and G. K. S. Prakash, J. Org. Chem., 2009, 74, 487.

7 P. L. Spath and D. C. Dayton, Preliminary screening - technical and economic assessment of synthesis gas to fuels and chemicals with emphasis on the potential for biomass-derived syngas, NREL/TP-510-34929, 2003.

8 A. de Klerk and E. Furimsky, Catalysis in the Refining of Fischer-Tropsch Syncrude, Chapter 2: Production of Synthesis Gas, Royal Society of Chemistry, 2010.

9 E. F. Sousa-Aguiar and L. Gorenstin Appel, Catalysis, 2011, 23, 284.

10 Y. Ohno, et al., NKK Technical Review no. 85, 2001, pp. 23-28; Y. Ohno, Kagaku Keizai, 2004, 89-93.

11 T. Matsushita, T. Haganuma and D. Fujita, US Pat., 2013/ 0237618 A1, 2013.

12 http://carbonrecycling.is/, accessed in Dec 2016.

13 A. M. Shulenberger, F. R. Jonsson, O. Ingolfsson and K.-C. Tran, US Pat., 2007/0244208 A1, 2007.

14 Blue Fuel Energy, http://bluefuelenergy.com/, accessed in $01 / 2017$.

15 G. Jacobs and B. H. Davis, Catalysis, 2007, 20, 122.

16 G. C. Chinchen, P. J. Denny, D. G. Parker, M. S. Spencer, K. C. Waugh and D. A. Whan, Appl. Catal., 1987, 30, 333-338. 
17 C. Kuechen and U. Hoffmann, Chem. Eng. Sci., 1993, 48, 3767.

18 K. Klier, V. Chatikavanij, R. G. Herman and G. W. Simmons, J. Catal., 1982, 74, 343.

19 K. Law, J. Rosenfeld and M. Jackson, Methanol as a renewable energy resource - White paper, TIAX LLC, 2013, http:// www.methanolfuels.org/wp-content/uploads/2013/05/MIRenewable-Methanol-Pathways-White-Paper_final.pdf, accessed 03/2017.

20 L. Chen, Q. Jiang, Z. Song and D. Posarac, Chem. Eng. Technol., 2011, 34, 817.

21 Report: GHG emissions of Blue Fuel methanol production process, (S\&T)2 Consultants Inc, 2010, http:// www.methanolfuels.org/about-methanol/environment/, accessed in $03 / 2017$.

22 J. Haid and U. Koss, Lurgi's Mega-Methanol technology opens the door for a new era in down-stream applications, Stud. Surf. Sci. Catal., 2001, 136, 399-404.

23 M. Cheiky and J. Hillier, US Pat., 8,835,517, 2014.

24 J. Sun, G. Yang, Y. Yoneyama and N. Tsubaki, ACS Catal., 2014, 4, 3346.

25 X. D. Peng, B. A. Toseland and P. J. A. Tijm, Chem. Eng. Sci., 1999, 54, 2787.

26 Y. Ohno, M. Yoshida, T. Shikada, O. Inokoshi, T. Ogawa and N. Inoue, JFE Technical Report No. 8, 2006.

27 X. D. Peng, A. W. Wang, B. A. Toseland and P. J. A. Tijm, Ind. Eng. Chem. Res., 1999, 38, 4381.

28 X. D. Peng, B. W. Diamond, T. C. R. Tsao and B. L. Bhatt, US Pat. , 6,458,856, 2002.
29 T. Shikada, Y. Ohno, T. Ogawa, M. Mizuguchi, M. Ono and K. Fujimoto, US Pat., 6,147,125, 2000.

30 J. M. Douglas, Conceptual design of chemical processes, McGraw-Hill, London, 1988.

31 T. Ogawa, N. Inoue, T. Shikada and Y. Ohno, J. Nat. Gas Chem., 2003, 12, 219.

32 W. M. Haynes, CRC Handbook of Chemistry and Physics, CRC press, Taylor \& Francis Group, London, 93rd edn, 2012.

332011 Guidelines to Defra/DECC's GHG Conversion Factors for Company Reporting: Methodology Paper for Emission Factors, August 2011, http://www.defra.gov.uk.

34 P. Patnaik, A Comprehensive Guide to the Hazardous Properties of Chemical Substances, Chapter 19: Gases, Common Toxic, and Flammable, John Wiley \& Sons, Inc., 2007, pp. 402-409.

35 A. Roy, S. Watson and D. Infield, Int. J. Hyd. Eng., 2006, 31, 1964.

36 L. Kleiminger, T. Li, K. Li and G. H. Kelsall, RSC Adv., 2014, 4, 50003.

37 Haldor Topsoe, http:/www.topsoe.com/, accessed in 09/ 2016.

38 L. Kleiminger, T. Li, K. Li and G. H. Kelsall, Electrochim. Acta, 2015, 179, 565.

39 Q. Fu, C. Mabilat, M. Zahid, A. Brisse and L. Gautier, Energy Environ. Sci., 2010, 3, 1382.

40 G. A. Olah and G. K. S. Prakash, US Pat., 8,791,166, 2014.

41 N. von der Assen, J. Jung and A. Bardow, Energy Environ. Sci., 2013, 6, 2721.

42 J. Bøgild Hansen, Faraday Discuss., 2015, 182, 9. 